\title{
Gender differences in language are small but matter for disorders
}

\author{
Mikkel Wallentin ${ }^{1,2,3, *}$
}

1) Department of Linguistics, Cognitive Science and Semiotics, Aarhus University, Jens Chr. Skous Vej 2, 8000 Aarhus C, Denmark;

2) Center of Functionally Integrative Neuroscience, Aarhus University Hospital, Aarhus, Denmark;

3) Interacting Minds Centre, Aarhus University, Aarhus, Denmark

*) Corresponding author

Email: mikkel@cc.au.dk 


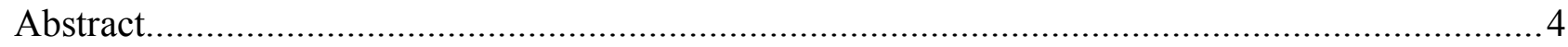

Why should neuroscientists care about language?........................................................... 5

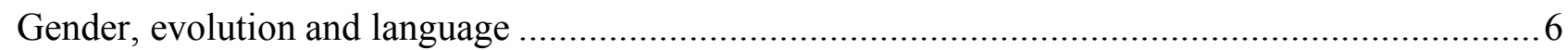

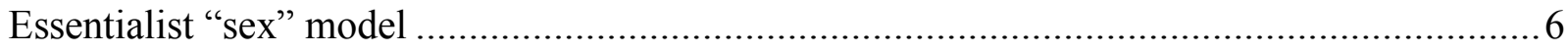

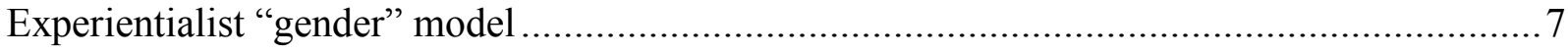

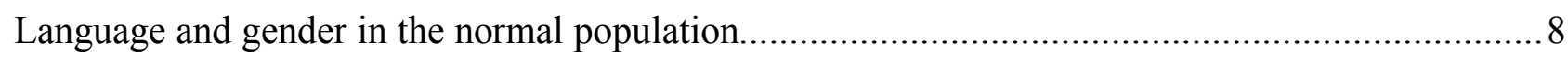

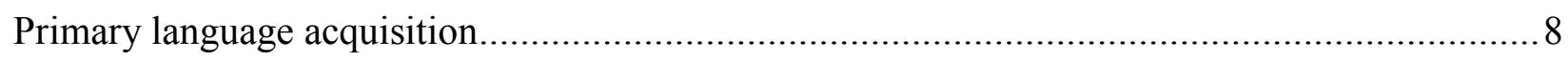

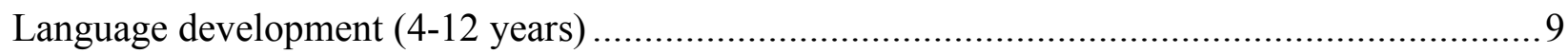

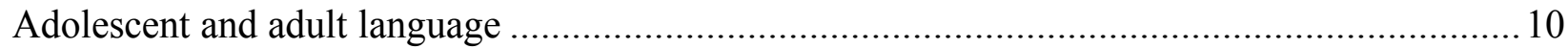

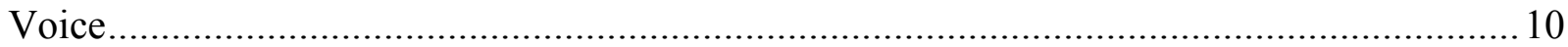

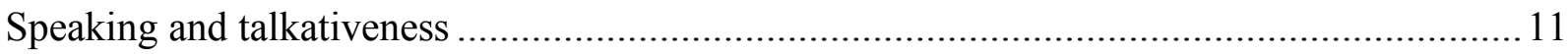

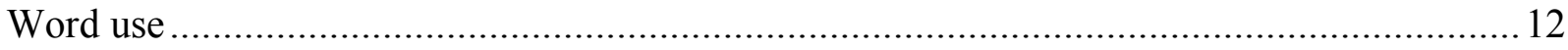

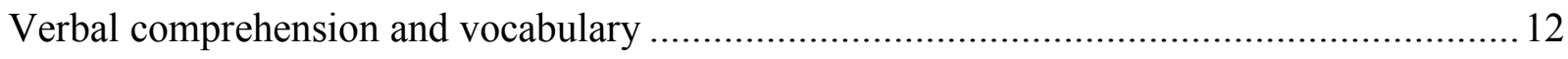

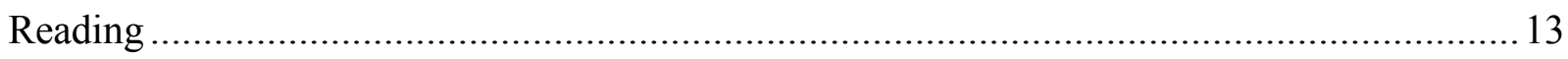

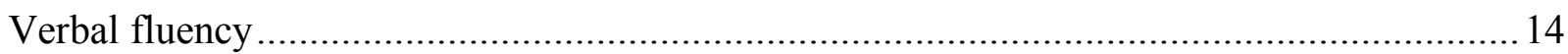

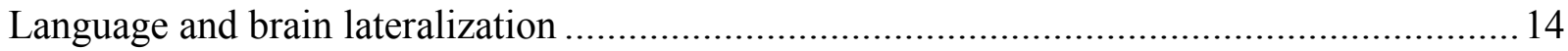

Language and gender in disorders and in the diseased brain ............................................. 15

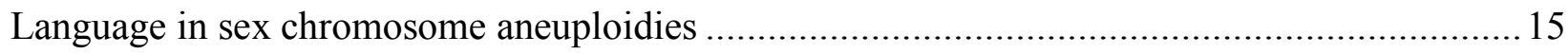

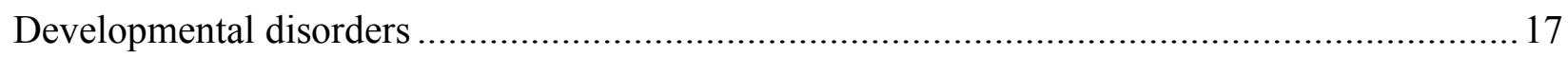

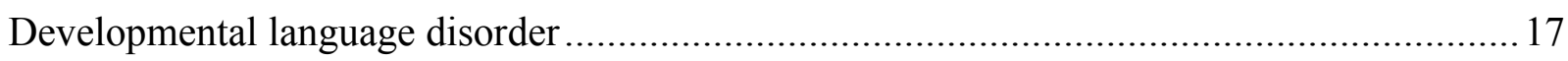

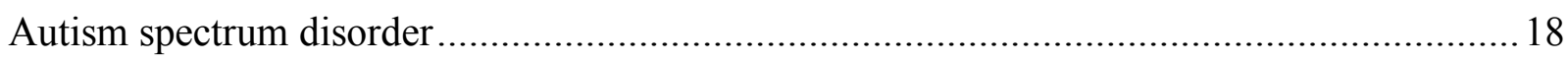

Childhood-Onset Fluency Disorder (Stuttering) ......................................................... 19

Specific learning disorder with reading impairment (dyslexia) ...................................... 20

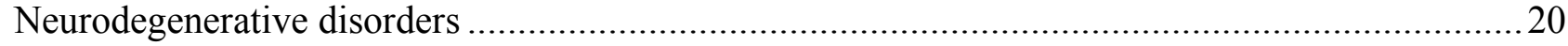

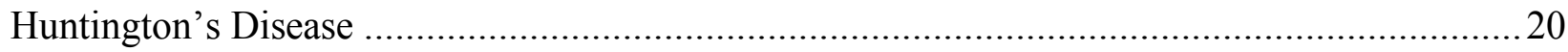

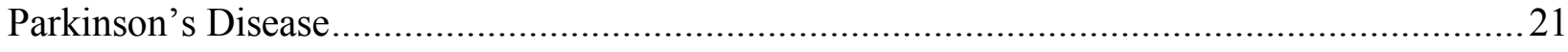

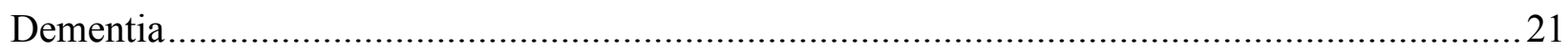

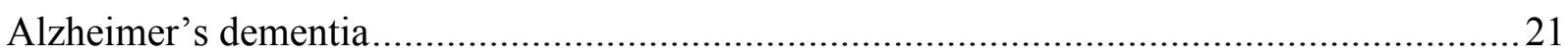

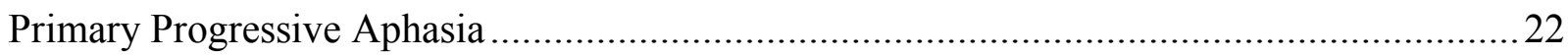

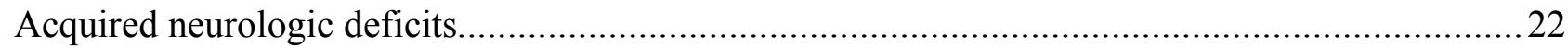

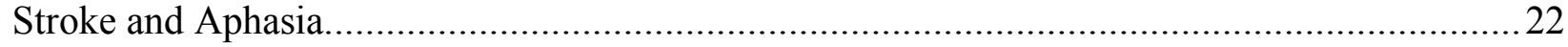

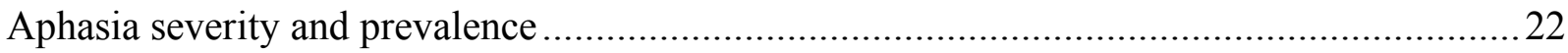

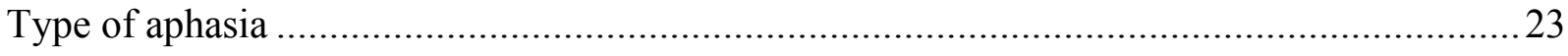

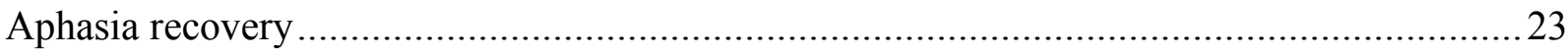

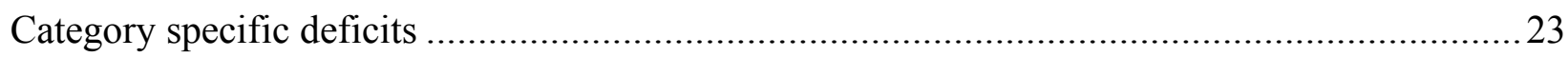

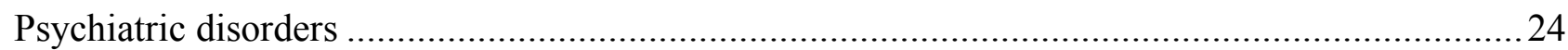


Submitted to: Lanzenberger, R., Kranz, G.S., Savic, I.(eds.), Handbook of Clinical Neurology: Sex differences in neurology and psychiatry, Elsevier, March 11, 2019

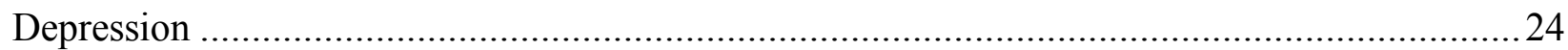

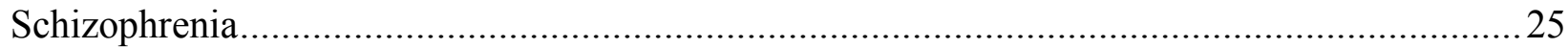

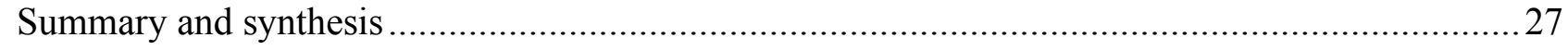

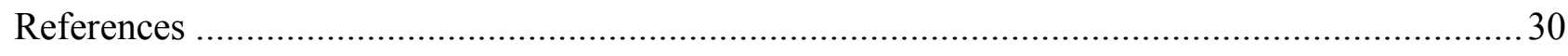

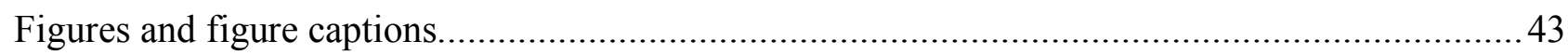

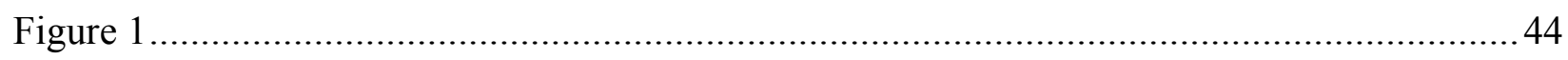

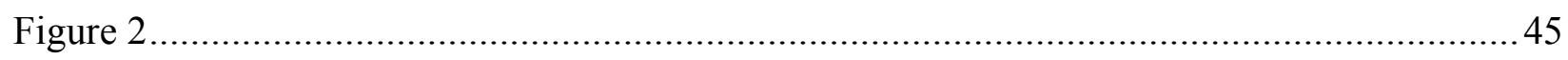

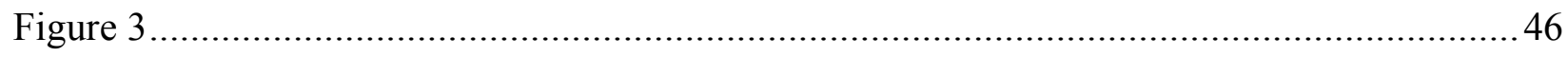

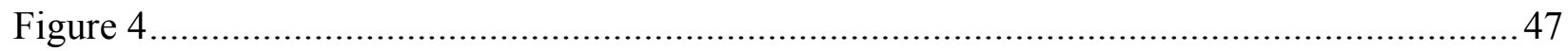

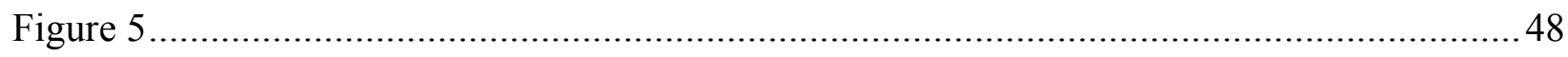

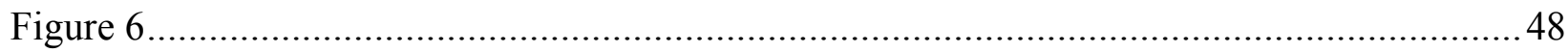




\section{Abstract}

Language is omnipresent in human life and therefore also in the brain. Gender differences in language can be signs of cognitive differences, but can also by themselves be the cause for such differences. Females have a slight linguistic advantage to males, but effect sizes are small and gender explains very little of the variance seen in the normal population (1-2\%). However, males outnumber females in the lowest $10^{\text {th }}$ percentile in language tests $(2: 1)$, causing males to more often be diagnosed with developmental disorders which rely on tests of language development. Thus, gender differences in language are negligible, if you focus on the whole population, but if you focus on language deficits, gender differences are outspoken. Differences in voice and word-use can be observed among the genders, making it possible to predict gender from these measures with a high degree of certainty. A subtle finding is that women use more $1^{\text {st }}$ person pronouns. This is also observed in depression which is more prevalent in females, opening up for a potential link. Sex chromosome trisomies are often accompanied by language deficits, but the causes for this are not known. No gender differences are observed in the linguistic symptoms of neurodegenerative disorders. Post-stroke aphasia is more prevalent among women than among men, but this seems to be an age-effect. A link between the brain and gender differences in language is thus missing.

Keywords: Language, language acquisition, vocabulary, reading, dyslexia, aphasia, gender differences 


\section{Why should neuroscientists care about language?}

Humans speak around 16,000 words per day (Mehl et al., 2007). This amounts to around 1,000 words every waking hour or 16 per minute (at a $500 \mathrm{~ms} /$ word rate), and this is just speaking. If we add listening to conversation, reading, writing, texting, social media, television and inner dialogue, we realize that language is omnipresent in our lives, from before we learn to speak until we die.

Language modulates and potentiates brain plasticity. The main evolutionary driver for neural systems is to allow an organism to respond flexibly to the environment and learn from its experiences in an adaptive manner. Language provides leverage for this learning system while in the process taking over large parts of the attentional space. Language is thus an important tool for interacting minds (Tylén et al., 2010), and linguistic exchange gives humans their unique abilities to collaborate and to acquire knowledge without firsthand experience.

Language is a part of everything we do and affects all aspects of behavior and cognition, including eye movements (Tanenhaus et al., 1995; Wallentin et al., 2011), perception of color (Winawer et al., 2007; Regier et al., 2007; Roberson et al., 2005; Maier and Abdel Rahman, 2018), perception of space (Levinson, 2003; Wallentin et al., 2008), respiration (MacLarnon and Hewitt, 1999), posture (Yardley et al., 1999), conditioning (Phelps et al., 2001), imagery (Stroustrup and Wallentin, 2018; Wallentin et al., in press), sleep (Petit et al., 2007), and even anatomy exam performance (Stephens and Moxham, 2018). Following from this, there is a language component to almost all neurologic and psychiatric deficits. A loss of language due to brain disease is furthermore one of the worst imaginable handicaps (Lam and Wodchis, 2010). It distances the patient from other people and changes her/his identity and personality.

Early language deficits are also cause for and/or indications of psychopathology. Fifty percent of children seen in mental health clinics and in special classrooms for children who have socialemotional problems have some language impairment and the same proportion of children referred to speech-language pathologists or to special education classes for learning disabilities have a social-emotional problem (Im-Bolter and Cohen, 2007). Longitudinal studies have documented the association between developmental language impairment, psychiatric disorder, poor social 
competence and well-being (Beitchman et al., 2001; Conti-Ramsden and Botting, 2008;

Whitehouse et al., 2009; Chow et al., 2018).

\section{Gender, evolution and language}

Theories about interactions between cognition and gender have a long and controversial history. Darwin wrote that "Man is more courageous, pugnacious and energetic than woman, and has a more inventive genius" (Darwin, 1889, p. 557). Galton "found as a rule that men have more delicate powers of discrimination than women" (Galton, 1892, p. 20). However, already with Darwin and Galton, it is hard to disentangle science from personal prejudice and political ideology (Buss, 1976; Denmark et al., 2008), something that has riddled the study of gender differences in cognition ever since, exemplified by statistically significant effects of author gender on outcome measures in gender difference research (Hyde and Linn, 1988).

Views similar to those of Darwin and Galton are still shared by many people today. Gender researchers (Kite et al., 2008; Haines et al., 2016) have identified two principal dimensions in gender stereotypes: beliefs that women are primarily occupied with the welfare of other people (labeled expressive or communal) and beliefs that men are assertive and controlling (labeled instrumental or agentic). Part of the female expressive stereotype includes that women are supposedly more verbally skilled than men (Cejka and Eagly, 1999).

\section{Essentialist "sex" model}

Essentialists regard cognitive differences between women and men as natural, fixed, deep-seated, discrete, and related to biological sex (Skewes et al., 2018; Haslam et al., 2000).

Seen through an evolutionary lens, two possibilities arise if a cognitive trait is heritable: The trait can either be transmitted equally to both sexes or unequally. This gives rise to two hypotheses: The gender similarity hypothesis (Hyde, 2005; Hyde, 2014) or a sexual difference hypothesis (e.g. Cahill, 2006; Buss and Schmitt, 1993; Miller, 2000; Baron-Cohen et al., 2005; Kimura, 2004).

The basis for an evolutionary pressure leading to sexually divergent traits could be a long-term division of labor between the sexes, hypothesized to be present in prehistoric groups of 
hunter/gatherer foragers (Marlowe, 2007). Another possibility is that divergent traits arise through within-sex competition or as sexual fitness display, usually in males (Miller, 2000; Locke and Bogin, 2006; Lange et al., 2014). These two theories predict opposite outcomes for sex differences in language skills. The hunter/gatherer theory posits that women have better developed social (and hence verbal) skills due to spending more time in groups and with offspring, while the sexual display hypothesis posits that language is a runaway trait selected for its aesthetic features like the tail-feather of the peacock. The consequence of the latter process, where language is used to signal a healthy cognitive system during sexual selection, would be that males compete to become better speakers while females would benefit from being better listeners (Rosenberg and Tunney, 2008).

Regardless of theory, however, an essentialist sexual difference hypothesis based on natural selection would in the long run lead to clearly separable distributions of the particular cognitive traits.

The gender similarity hypothesis, on the other hand, as formulated by Hyde $(2005 ; 2014)$, states that males and females are similar on most, but not all, cognitive variables (Hyde, 2005). Hyde presented evidence for the hypothesis using meta-analyses on 124 cognitive and psychological gender difference measures and found that $30 \%$ of the effect sizes were effectively 0 (Cohen's d: 0 0.10 ), and an additional $48 \%$ were in the range of a small difference, between 0.11 and 0.35 . Thus, Hyde found that almost $80 \%$ of the gender difference measures evaluated were either small or zero, arguing against any categorical gender divide in psychological traits.

\section{Experientialist "gender" model}

Gender differences may also arise without being hardwired. Given the plasticity of the human brain, especially under the influence of language, any difference in behavior or practice could hypothetically lead to differences at the neural level. The longer and more vigorously such differences are maintained during the lifespan of an individual, the deeper entrenched the differences will become. The origin of such differences in behavior could be historical, cultural or otherwise contextual. Observed gender differences in language and brain, seen in this perspective, may be reflections of differences in gender roles in a society. 
Importantly, however, experientialist linguistic differences can also be thought to arise as a side effect of innate sex differences in non-linguistic domains, modulated and/or expressed with the help of language and with gender differences in linguistic behavior as a result. Language may both be the cause and the effect.

These three perspectives give rise to three different hypotheses: 1) If innate sex differences exist in language, we should expect to see strong behavioral effects and similar sexually dimorphic brain functions and structures subserving these differences; 2) If gender differences in language are only due to cultural factors, we should expect to see no universal differences and furthermore, any difference observed should in principle be reversible, depending on the constraints on brain plasticity; 3) If language interacts with non-linguistic sex differences, we may see universal linguistic effects, but these may be much less categorical than "proper" sex differences and may not necessarily be underpinned by a clearly dimorphic brain.

Lastly, it is possible that we may find traces of all of the above functions across different measures of language function.

\section{Language and gender in the normal population}

\section{Primary language acquisition}

Children usually start speaking their first words when they are around 12 months old (Tomasello, 2003). First language acquisition is most commonly studied using parental reports such as the MacArthur-Bates Communicative Development Inventories (Fenson et al., 1994), where parents go through a list of 600-800 words (depending on language) and report whether their child has produced/understands each individual word. Across multiple languages, it has been found that girls begin to speak slightly earlier and understand and produce significantly more words than boys (e.g. Fenson et al., 1994; Bleses et al., 2008; Berglund et al., 2005; Simonsen et al., 2013; Frota et al., 2016). The effect size is relatively small, accounting for $1-2 \%$ of the variance. A synthesis of data from studies in 10 different languages (Austrian German, Basque, Croatian, Danish, Estonian, French, Galician, Slovene, Spanish and Swedish), including $>13,000$ children replicated that girls are slightly ahead of boys in early communicative gestures, in productive vocabulary, and in combining words (Eriksson et al., 2011). Boys were not found to be more variable than girls. Data 
from the CDI: Words and Sentences is available from more than 28,000 children at http://wordbank.stanford.edu. This database covers a large number of languages, including Cantonese (Tardif et al., 2009), Croatian (Kovacevic et al., 1996), Czech (Markova and Smolík, 2013), Danish (Bleses et al., 2008), English (US) (Fenson et al., 2007; Thal et al., 2013), English (AU) (Kalashnikova et al., 2016), German (Szagun et al., 2009), Hebrew (Hila Gendler Shalev, Tel-Aviv University), Italian (Caselli et al., 1995), Korean (Pae and Kwak, 2011), Latvian (Urek et al., to appear), Mandarin (Tardif et al., 2009; 劉惠美 and 陳昱君, 2015), Norwegian (Simonsen et al., 2013), Portuguese (European) (Irene Cadime, University of Minho), Russian (Елисеева and Вершинина, 2009), Slovak (Svetlana Kapalková, Comenius University), Spanish (European) (López Ornat et al., 2005), Spanish (Mexican) (Jackson-Maldonado et al., 2003), Swedish (Eriksson and Berglund, 2002) and Turkish (Acarlar et al., 2009). Focusing on the number of produced words at the 16-30 months age range where the inventory has best coverage (see figure 1A), it can be seen that gender differences vary slightly with age, such that at 26 months of age, the median boy produces 330 different words, while the median girl produces 414 words. Across languages, gender explains approximately $1 \%$ of the variance. Variability for younger children is influenced by floor effects and for older children by ceiling effects as many children will have begun to produce all the words in the wordlists. While the amount of explained variance is small (Cohen's $d \approx 0.2-0.4$, see figure 1B), the pattern is near universal: Girls outperform boys in 19 out of the 21 sampled language areas. Furthermore, the difference is more outspoken among the lowest scoring children. In the low $10^{\text {th }}$ percentile boys outnumber girls at a 2:1 ratio at 26 months of age (figure $1 \mathrm{C}$ ).

\section{**FIGURE 1 AROUND HERE**}

\section{Language development (4-12 years)}

Studies on preschool development have found that the growth in vocabulary shows comparable slopes for boys and girls, suggesting that boys on average acquire language with a slight delay, rather than being on a different trajectory (Jiang et al., 2018; Bornstein, 2004). Longitudinal data from the Twins Early Development Study (TEDS) on British children (Hayiou-Thomas et al., 2012) measured vocabulary at 7 years $(n=3329), 9$ years $(n=2177), 10$ years $(n=1686)$ and 12 years $(n=2900)$ of age using the vocabulary subtest of the WISC -III (Wechsler, 1992). While gender differences in language had also been consistently found using the CDI method in early childhood 
in this sample, no significant gender differences were observed at 7-12 years, except for 10 years, where a surprising slight advantage for boys was observed. This effect, however, straddled the boundary of significance and, given the other null-results, is probably a false positive. Interestingly, however, the same children were also evaluated by their teachers on their overall oral language skills, using the UK National Curriculum's Speaking \& Listening criteria. Here, a small, but consistent advantage for girls was found with effect sizes around Cohen's $d \approx 0.2$ for all age groups. There are two possible explanations for this inconsistency. Either the "Speaking and Listening" evaluation picks up on language skills that the vocabulary test does not, or the teachers are biased towards evaluating the girls' language competences as better than the boys. Tests of figurative language, inferences and syntax at 12 years did not yield significant gender differences.

Another study (Dale et al., 2010) on the (TEDS) data found a small difference in the Listening/Grammar subtest of the Test of Adolescent Language-3 (Hammill et al., 1994) and in reading fluency (Tosto et al., 2017), but also found that there were no quantitative differences in etiology for the sexes, that is, no differences in the balance of genetic or environmental factors on language comprehension skills were observed.

A nationally representative UK sample of over 320,000 school pupils aged 11-12 years from 20012003, on the other hand, found that girls scored higher than boys on verbal reasoning tests (word classification, sentence completion and verbal analogies). The effect size was again small $(d=0.15)$, but below the $10^{\text {th }}$ percentile, boys outnumbered girls at 1.42:1. Taken together, this suggests that girls' small early linguistic advantage is also present at age 12 , but that it may be so small that it is not meaningful. The observed overrepresentation of boys in the lowest percentiles, however, indicates that $60 \%$ of all 12 -year old children with serious language issues are boys.

\section{Adolescent and adult language}

Voice

Adult males have deeper voices than adult females. The mean fundamental frequency (F0) of a voice is associated with the perceptual notion of pitch. Pitch constitutes a major difference between the sexes. Mean F0 is around $125 \mathrm{~Hz}(\mathrm{SD}: 20 \mathrm{~Hz}$ ) for adult men and $230 \mathrm{~Hz}(\mathrm{SD}: 23 \mathrm{~Hz})$ for women (Figure 2B) (Bachorowski and Owren, 1999). The primary difference is due to the size of 
the vocal organs related to overall body size (figure $2 \mathrm{~A}$ ). The male and female membranous vocal fold length differ by a 1.6:1 factor (Titze, 1989). This accounts for the difference in produced F0, airflow and aerodynamic power. Gender classification can be conducted with almost $100 \%$ accuracy on the basis of extracted sound features, even from a short vowel segment alone (Bachorowski and Owren, 1999; Childers and Wu, 1991). Vowel formant frequencies have been found to differentiate gender for children as young as four years of age (Perry et al., 2001). Voice breaking in boys is clearly related to biological sex and F0 in adolescents is strongly correlated with testicular size (Harries et al., 1997) and bioavailable testosterone (Markova et al., 2016). It has been found that heterosexual women find a low-pitched voice more attractive (Feinberg et al., 2006) while men prefer higher pitched female voices (Feinberg et al., 2008), but it has also been suggested that male intrasexual competition for dominance was a salient selection pressure for voice frequency (Puts et al., 2006). For both sexes, rated voice attractiveness have been found to predict reported age of first sexual intercourse and number of sexual partners (Hughes et al., 2004), indicating sexual selection pressure.

\section{**FIGURE 2 AROUND HERE**}

\section{Speaking and talkativeness}

A study of 396 US and Mexican university students (Mehl et al., 2007) wearing automatic recording devices found that women on average speak 16,215 words per day while men speak on average 15,669 words per day. This difference (Cohen's $d=0.07$ ) was not statistically significant. A meta-analysis (Leaper and Ayres, 2007) based on 70 studies and 4385 participants, on the other hand, found men to be significantly more talkative than women, although the effect was small $(d=-$ 0.14). Men $(d=.09)$ were found to use more assertive speech (i.e. verbal acts that seek to influence the listener), while women $(d=.12)$ used more affiliative speech (such as agreement and support that affirm the speaker's connection to the listener). Another meta-analysis (Leaper and Robnett, 2011) based on 3,502 participants found that women were more likely to use tentative speech (such as hedges, qualifiers/disclaimers, tag questions). Again, the effect size was small $(d=0.23)$. A study of 500,000 Mexican phone users' phone calls over a duration of 3 months revealed that women were on the phone for a total of 167 minutes on average, while men were on the phone for 177 minutes (Sarraute et al., 2014). Together, these results make it difficult to find support for the 
hypothesis that females are more "expressive" than males and effect sizes are generally so small that they do not have much real-world relevance.

\section{Word use}

Word use have been found to be predictive of gender both in natural conversations (Mehl and Pennebaker, 2003), in written texts (Newman et al., 2008), and on social media (Sap et al., 2014; Schwartz et al., 2013). Not so surprisingly, words like "boyfriend", "earrings", "heels" and "makeup" are highly correlated with the female gender, while words like "girlfriend", "boxers", and "beard" are predictive of male gender (see figure 3) (Sap et al., 2014). Using multivariate classification based on word use on Facebook, gender can be predicted with $80-90 \%$ accuracy across different languages (Sap et al., 2014; Basile et al., 2018; Cheng et al., 2011). Revealing your gender through grammar is actually obligatory in some languages, such as French. Here, high gender classification rates can be achieved simply by investigating constructions such as "I am.../Je suis..." where the following adjective in French will most often take on the gender of the speaker (e.g. Je suis heureux vs Je suis heureuse) (Ciot et al., 2013). Emotions are also expressed differently by the two genders on social media: Females use more words related to positive emotions, but also anxiety and sadness, while males use more words related to negative emotions (e.g. swear words), especially anger (Newman et al., 2008; Schwartz et al., 2013). Focusing on high-frequency function words (articles, prepositions, conjunctions, and pronouns), females have consistently been found to use more first-person singular pronouns (“I”, "me”, "my”) while males use more articles (“a”, "an”, "the"), which serves as a proxy for males using more nouns (Newman et al., 2008; Schwartz et al., 2013; Beach et al., 2016; Mehl and Pennebaker, 2003). Again, effect sizes are small (Cohen's $d \approx$ $0.2)$.

\section{**FIGURE 3 AROUND HERE **}

\section{Verbal comprehension and vocabulary}

A very famous meta-analysis (Hyde and Linn, 1988) investigated 165 studies that reported data on gender differences in verbal ability and found a small female superiority in performance $(d=0.11)$. The authors concluded that the difference was so small that "gender differences in verbal ability no longer exist". The question is if this conclusion still holds and if the presence of even small 
differences could somehow still matter, e.g. if it leads to bigger differences in the parts of the distribution where language problems are experienced?

One large study, conducted around the same time as the Hyde and Linn data, points to a slightly higher, but still small effect size among young adults. From 1971 to 1984, the Israeli Defense Forces each year administered IQ tests to almost all 17 year old citizens (Flynn, 1998). A total of 328,597 participated $(169,661$ males, 158,936 females $)$. On the verbal instructions test with items such as "write the last letter of the word which is the opposite of black", females scored higher every year on average $(d=0.19)$. No effect was found for nonverbal IQ.

A more recent meta-analysis (Voyer and Voyer, 2014) on gender differences in scholastic achievement for language courses in elementary, junior/middle, or high school and university levels found a consistent female advantage with a somewhat larger effect size $(d=0.37)$ than the one reported by Hyde and Linn.

\section{Reading}

Reading habits and print exposure is known to be correlated with other elements of language proficiency (Acheson et al., 2008; Cunningham and Stanovich, 1991). While language ads gears to learning, reading ads a gear to language. Reading proficiency thus has a "Matthew effect" (every one that hath shall be given) on language (Stanovich, 1986). It has been suggested that children (aged 4-15) who read a lot learn 4 words per day on average while children who do not read much only learn 1.5 words per day (http://testyourvocab.com/blog/2013-05-09-Reading-habits). Chiu \& McBride-Chang (2006) reviewed reading comprehension tests from 43 countries, with a total of 199,097 fifteen-year-old children. In every country, girls outscored boys. Differences in reading enjoyment accounted for approximately $40 \%$ of the gender effect. The Program for International Student Assessment (PISA - http://www.oecd.org/pisa/) has found similar effects. Girls on average outperform boys on the overall reading scale in all OECD and partner countries (see figure 4 for 2015 data from 73 countries at age 15). This finding documents a clear and seemingly universal gender difference. Data from 2000, 2003 and 2006 estimated the girls' advantage to be a Cohen's $d$ of $0.49,0.36$, and 0.41 , respectively ( $d=0.42$ on average) (Lynn and Mikk, 2009). Effect sizes are thus small-medium and path models from a Finish PISA sample found that gender accounts for 2$6 \%$ of the variance (Torppa et al., 2017). A larger number of boys are found in the lowest tail of the 
reading skill distributions. The risk of being among the lowest-scoring 10\% on PISA is $2.4: 1$ for boys (see figure 4). The risk of being among the lowest-scoring $10 \%$ in reading fluency is $4.4: 1$ (Torppa et al., 2017).

If we argue that the initial small gender difference in language is due to a delay rather than an actual difference, then variability in reading habits, on the other hand, have the potential of transforming the delay into a permanent difference. Further, if boys who have language learning problems are also struggling with reading (see below), they may become permanently trapped in the lowest percentiles of the language proficiency distribution.

\section{**FIGURE 4 AROUND HERE **}

\section{Verbal fluency}

Verbal fluency (also known as The Controlled Oral Word Association Test) is often mentioned as a task which displays gender differences. The test involves naming as many words as possible in a minute, starting with either a specific letter (the phonemic task) or belonging to a specific category (e.g. animals). A meta-analysis (Barry et al., 2008) including 134 studies found no gender difference on the verbal fluency task, but clear effects of education and age.

\section{Language and brain lateralization}

The idea that men are more lateralized than women gained popularity in the 1970's (Levy and Reid, 1978; Harris, 1978; McGlone, 1980), but dates back more than 100 years (Crichton-Browne, 1879). The idea captured the popular imagination, although it was controversial from the beginning (e.g. Fairweather, 1982). During the early years of functional imaging, a number of influential studies supported the early claims by reporting a more bilateral pattern of activity during language processing in women compared to men (e.g. Kansaku et al., 2000; Phillips et al., 2001; Shaywitz et al., 1995). However, a meta-analysis on 26 studies (including more than 2,100 participants) found no significant effect of sex on language lateralization in functional imaging studies, neither in children nor in adults (Sommer et al., 2008; Sommer, 2004). Several methodological issues with studies on sex differences in language lateralization have been raised (Wallentin, 2009; Kaiser et al., 2009; Rippon et al., 2014), one of these being publication bias favoring positive effects. However, since the publication of Sommer and coworkers' meta-analyses, a number of studies have 
been published that replicate the null-finding in lateralization difference (e.g. Wallentin et al., 2014; Hirnstein et al., 2013; Somers et al., 2015; Nenert et al., 2017).

Historically, the idea that males are more lateralized has been linked to prenatal testosterone exposure (Geschwind and Galaburda, 1985). However, a meta-analysis on the effect of prenatal testosterone exposure on the direction of lateralization did not find an effect in humans (Pfannkuche et al., 2009). It thus seems that the gender differences observed in verbal behavior are uncoupled from brain lateralization (Hirnstein et al., 2018).

\section{Language and gender in disorders and in the diseased brain}

\section{Language in sex chromosome aneuploidies}

Sex chromosome syndromes represent an obvious test-case for whether parts of language function are tied to genetic sex. A number of different sex chromosome aneuploidies exists. Here, only the trisomies will be discussed: 47, XXY (Klinefelter syndrome), 47, XYY (XYY syndrome) and 47, XXX (Triple X syndrome).

Klinefelter syndrome (KS), 47,XXY, is the most frequent sex chromosome syndrome (1 per 660 live born males) (Gravholt et al., 2018). People with KS are phenotypically male, but have an extra $\mathrm{X}$ chromosome. They typically have small testes, hypergonadotropic hypogonadism and testosterone deficiency along with a number of more or less outspoken neural, cognitive and psychological traits (see Gravholt et al., 2018 for an extensive review). Given that people with KS have an extra X-chromosome and lack testosterone, one could expect their linguistic profile to lean towards the stereotypic female profile. This, however, turns out not to be the case. KS people score significantly below education matched controls on a range of cognitive tests with verbal skills displaying the largest effects (Skakkebæk et al., 2015). KS males exhibit deficits in different language domains, including verbal fluency (Boone et al., 2001) and general expressive skills (Rovet et al., 1996). Reading, writing, and literacy are also heavily affected in KS persons (Rovet et al., 1996). A study found that speech and language therapy was needed for $47 \%$ of boys with KS, compared to $18 \%$ among their male siblings (Bishop et al., 2009). Approximately $50 \%$ of both children and adults with KS show some level of dyslexia (Bender et al., 1986). Different genetic 
functions (Vawter et al., 2007; Bishop and Scerif, 2011) have been suggested to explain the language problems, but none have been replicable so far.

The XYY (47, XYY) syndrome affects one in 1,000 phenotypical males (Ross et al., 2009). Contrary to KS, people with XYY syndrome usually have normal testosterone levels (Bardsley et al., 2013). XYY syndrome persons display similar linguistic effects to those seen in KS, although they can be more severe (Ross et al., 2009). More than $70 \%$ of 47 XYY boys were found to receive speech and language therapy, compared to $18 \%$ among their nonaffected male siblings (Bishop et al., 2009). Verbal impairments include difficulty in naming, receptive vocabulary, and oral fluency (Hong and Reiss, 2014). Reading and spelling have also been found to be affected to a similar or worse degree than what is seen in KS (Ross et al., 2009).

Trisomy X (TX), 47, XXX, is the most common female chromosomal abnormality, occurring in approximately 1 in 1,000 female births (Tartaglia et al., 2010). TX females also display language problems in the form of speech delays in conjunction with other cognitive deficits and learning disabilities (ibid). $40 \%$ of 47 , XXX girls received speech and language therapy, compared to $4 \%$ among their female siblings (Bishop et al., 2009).

Viewing these effects together, one finds that the different sex chromosome trisomies share a tendency to give rise to problems with language and communication (Bishop and Scerif, 2011). Supporting this, sex chromosome trisomies have been found to be overrepresented in random samples of children with language and reading disorders (Simpson et al., 2013). The finding that a large proportion (40-70\%) of trisomy persons have a history speech and language therapy (Bishop et al., 2009) suggest that a link exists between language development and the burden of an extra sex chromosome, and the fact that $47, \mathrm{XYY}$ boys have the highest rates suggests that adding a Y chromosome may be more detrimental than adding an extra $\mathrm{X}$ chromosome. Another study found that the addition of a Y chromosome had a greater impact on pragmatic language, while the addition of an X chromosome had a disproportionately greater impact on structural language (Lee et al., 2012). Further studies are needed to replicate these findings. 
All groups also have higher prevalence of autism spectrum disorder symptoms, although TX women may again be less affected (Skakkebæk et al., 2014; Bishop et al., 2009; Bruining et al., 2009; Tartaglia et al., 2010).

It is furthermore worth noting that in Turner syndrome, 45, X0, where a woman/girl only has one Xchromosome, language and literacy is usually found to be in the normal range (Murphy, 2009), despite other cognitive deficits. With respect to speech/language deficits, it thus seems that duplication of a sex-chromosome is more detrimental than haploinsufficiency.

Language lateralization in sex chromosome trisomies has also been investigated using functional imaging. One study found that KS men were less lateralized than a control group (van Rijn et al., 2008), but this finding has not been replicated (Wallentin et al., 2016), and a recent study failed to find atypical lateralization for any of the sex chromosome trisomies (Wilson and Bishop, 2018b). We thus find a somewhat specific language deficit related to sex chromosome functioning, but without any concrete neural correlate for it and given the small number of studied cases as well as the large within-group variability, research is still needed in order to fully understand the significance of these observations.

\section{Developmental disorders}

\section{Developmental Language Disorder}

Developmental Language Disorder (DLD), a condition in which there are unexplained and persistent difficulties with language acquisition, including vocabulary, sentence structure and discourse (American Psychiatric Association, 2013), affects 7-8 \% of children (Norbury et al., 2016b). Twin studies have suggested very strong heritability for DLD (Bishop et al., 1995; Lewis and Thompson, 1992), and language deficits have been found to be strongly comorbid with other cognitive function deficits (Trouton et al., 2002). No differences between persons with DLD and typically developing groups have been found in measures of brain lateralization (Wilson and Bishop, 2018a).

It has been known for many years that developmental language deficits are more prevalent in boys (Bendel et al., 1989). In accordance with this, a large study of children and adolescents (3-17 years) from Taiwan (Tseng et al., 2015) recently found an increasing gender discrepancy in DLD, going 
from 1.53:1 in 2004 to $1.83: 1$ in 2010. No explanation for this change is offered in the paper. In another recent large study, Norbury and coworkers identified children at risk and found a 2:1 male/female ratio (Norbury et al., 2016a). This is in line with the observations from CDI reports analyzed above, where boys outnumber girls $2: 1$ in the $10^{\text {th }}$ percentile of language production scores at 26 months of age (figure 1C). DLD may thus represent the tail of the normal language acquisition distribution.

\section{Autism Spectrum Disorder}

Autism Spectrum Disorder (ASD) involves persistent deficits in social communication and social interaction across multiple contexts, i.e. not restricted to language (American Psychiatric Association, 2013). A delay in the production of the first words, however, has always been one of the earliest red flags for ASD (Jones et al., 2014), and many ASD individuals have language deficits, ranging from complete lack of speech through language delays, poor comprehension of speech, echoed speech or stilted and overly literal language. Even when formal language skills (e.g., vocabulary, grammar) are age-appropriate, the use of language for reciprocal social communication is impaired in ASD (American Psychiatric Association, 2013). Prospective studies have confirmed that delays in communication and language development are apparent early in life in children later diagnosed with ASD (Mitchell et al., 2006; Jones et al., 2014). ASD and DLD co-occur above chance level, suggesting some degree of shared etiology (Bishop, 2010), and suggesting that the difference between diagnoses is not categorical, but related to differences in how overlapping symptoms are weighted. ASD has also been associated with peculiar tones of voice and disturbances of prosody. Most ASD individuals (70-80\%) develop functional spoken language, but a large proportion displays early atypical acoustic patterns and a meta-analysis has identified significant differences in mean pitch and pitch range (Fusaroli et al., 2016).

ASD is under a high degree of genetic control (Bailey et al., 1995; Sandin et al., 2014; Clarke et al., 2015 ) and shows a large sex difference. At 8 years of age, 1:42 boys will be diagnosed while 1:189 girls will receive the diagnosis (Autism and Developmental Disabilities Monitoring Network Surveillance Year 2010 Principal Investigators, 2014). With changing diagnostic criteria and increased awareness, these numbers have been changing which has also affected the male/female ratio to some extent (e.g. the same surveillance team found an ASD prevalence of 1:54 (boys) vs 1:252 (girls) in 2008). Within the group of children with an ASD diagnosis, no significant effects of 
sex have been found, suggesting a similar phenotype in males and females early in development (Reinhardt et al., 2015), although the genetic burden seems to be different (Vorstman et al., 2017).

\section{Childhood-Onset Fluency Disorder (Stuttering)}

The DSM-V criteria for stuttering (American Psychiatric Association, 2013) are early-onset disturbances in the fluency and time patterning of speech (inappropriate for the person's age) that interferes with communication and academic or occupational achievement.

Twin studies have revealed higher concordance for stuttering in monozygotic (63\%) than dizygotic twins (19\%), suggesting a genetic factor in stuttering (Howie, 1981). Stuttering most often reveals itself around the $2^{\text {nd }}$ to $3^{\text {rd }}$ year of age. A meta-analysis on studies of language competences in children with stuttering found that stuttering is accompanied by lower measures on overall language, receptive as well as expressive vocabulary and mean length of utterance (Ntourou et al., 2011). The meta-analysis looked at studies with age and gender-matched control groups and did not report gender differences. Further, it did not say whether the lower language competences reflect delayed acquisition or remain into adulthood. Another review, however, found that a large proportion (50-94 \%) of early stutterers show spontaneous recovery (Yairi and Ambrose, 2013). Stuttering actually has a well-known gender skew in prevalence. A survey of the literature for this article revealed 19 studies where observed stuttering rates for males and females could be established along with measures of uncertainty (McCulloch and Fawcett, 1964; Porfert and Rosenfield, 1978; Ardila et al., 1994; Månson, 2005; Craig et al., 2002; McKinnon et al., 2007; van Borsel et al., 2006; Dworzynski et al., 2007; Proctor et al., 2008; Mohamadi et al., 2008; Akhavan Karbasi et al., 2011; Rautakoski et al., 2012; McAllister et al., 2012; Kefalianos et al., 2014; Obeid et al., 2015; Abou Ella et al., 2015; Thapa et al., 2016; Mohamadi et al., 2016; Gerlach et al., 2018). No studies were found that did not report boys/men to be more prone to stuttering than girls/women (se figure 5A). The average gender ratio was found to be 2:1 across these studies.

\footnotetext{
**FIGURE 5 AROUND HERE**
} 
The studies, however, included participants in diverse age groups, both children and adults. Some studies were divided into several age groups (Craig et al., 2002; Dworzynski et al., 2007; Mohamadi et al., 2008; van Borsel et al., 2006). An interaction between gender and age has been observed for recovery, showing a longer recovery time in boys. (Månson, 2005) The survey looked at differences in gender prevalence as a function of age (see figure 5B). As can be seen from figure $5 \mathrm{~B}$, the gender difference never disappears, but diminishes to some extent from middle childhood into adulthood.

\section{Specific Learning Disorder With Reading Impairment (Dyslexia)}

Specific Learning Disorder (SLD) is defined as persistent difficulties in learning and using academic skills (American Psychiatric Association, 2013), which can be more or less selective for skills related to reading, writing or math. To become literate, the child needs to take a step from implicit to explicit control of the phonemic segments of language. The productive use of an alphabetic script requires an explicit awareness of the elusive phonemes and a conscious control of these units, so that they can be manipulated, substituted and recombined. This skill is called phonological awareness and its absence is the most important predictor of reading impairment (Lundberg et al., 2012; Lundberg et al., 1980). As indicated above, boys outnumber girls in the normal distribution of reading competences, and the lowest percentiles are likely to be diagnosed with SLD or Dyslexia. Depending on the diagnostic procedures, the gender ratio is found to be 1.69:1 to 4.51:1 (Miles et al., 1998). These numbers correspond well with the gender ratio found in the lowest $10^{\text {th }}$ percentile of the PISA reading test (see figure 4) and suggest that reading impairment is not a categorical deficit, but a distribution and that gender differences will vary according to how the cutoff between normal and abnormal is defined with respect to this distribution. A meta-analysis recently documented this effect and estimated the gender odds-ratio to be 1.83 (Quinn, 2018).

\section{Neurodegenerative disorders}

\section{Huntington's Disease}

Huntington's Disease (HD) is a neurodegenerative autosomal dominant disorder, caused by a CAG repeat expansion mutation in the HTT gene on the short arm of chromosome 4 (Walker, 2007) and 
usually appears between 30 and 50 years of age at equal rate in both genders. With respect to language, patients in late stages have been found to exhibit a loss of conversational initiative along with dysarthria (Podoll et al., 1988). HD patients exhibit no evidence of word-finding difficulty or other semantic deficits in spontaneous speech and a study of 1267 HD patients (Zielonka et al., 2013) found no gender difference in HD-specific, language related measures (verbal fluency, Stroop word task) at baseline and no language related differences as a function of disease progression.

\section{Parkinson's Disease}

Parkinson's Disease (PD) is a progressive neurodegenerative disease characterized primarily by motor symptoms, but also a variety of non-motor symptoms including cognitive decline (Taylor et al., 1986; Elgh et al., 2009). PD is more prevalent in men than in women with a 1.5:1 ratio (Wooten et al., 2004). Core language function is not directly affected by PD, but a worsening of verbal fluency is often observed (Taylor et al., 1986), both as an independent symptom of the disease and as a side effect of treatment. Later stages of PD are often treated with deep brain stimulation of the subthalamic nucleus (Deuschl et al., 2006). Worsening of verbal fluency after treatment with deep brain stimulation in PD patients is one of the most often reported cognitive adverse effect (Højlund et al., 2017). None of the meta-analyses on the verbal fluency effects in PD target gender differences (Parsons et al., 2006; Combs et al., 2015), but one study (Obeso et al., 2012), including 300 PD patients tested effects of gender in verbal fluency and found none.

\section{Dementia}

Dementia is a general term for a decline in mental ability caused by brain disease. Language is affected differently in different types of dementias (Klimova and Kuca, 2016).

\section{Alzheimer's Dementia}

In Alzheimer's Dementia (AD), language and communication are only severely affected in late stages of disease progression. Earlier signs are probably primarily linked to non-core linguistic processes, such as inability to concentrate. Verbal fluency tests, however, are significantly affected. Two meta-analyses (Henry et al., 2004; Laws et al., 2010) compared the magnitude of deficits upon tests of phonemic and semantic fluency for AD patients relative to healthy controls. It was found that $\mathrm{AD}$ patients were significantly more impaired on tests of semantic relative to phonemic 
fluency. This may imply a larger relative degradation of the semantic store. However, it may also simply be an exaggeration of a normal tendency for participants to score higher on the phonemic test (Laws et al., 2010) and as such reflect changes in executive functioning rather than linguistic abilities. Laws and coworkers (ibid.) found in their meta-analysis that studies with a greater proportion of female AD patients observed less severe degradation of both semantic and phonemic fluency, suggesting that females' verbal reserves are less vulnerable to AD or that women are simply less affected by the disease at the time of testing.

\section{Primary Progressive Aphasia}

Primary Progressive Aphasia (PPA) is a disorder of declining language originating in neurodegenerative diseases such as frontotemporal lobar degeneration. Three variants of PPA are recognized (Grossman, 2010): Progressive Nonfluent Aphasia, Semantic Dementia, and Logopenic Progressive Aphasia. No gender bias has been observed, neither in the frequency of PPA (Grossman, 2010; Hodges and Patterson, 2007), nor in frontotemporal dementia in general (Onyike and Diehl-Schmid, 2013).

The take-home message from this review of degenerative diseases is that language is affected, but not in a gender-specific manner. This argues against the existence of any largescale gender-specific neural systems for language.

\section{Acquired neurologic deficits}

\section{Stroke and Aphasia}

\section{Aphasia severity and prevalence}

On the surface, large-scale studies of post-stroke aphasia have been inconsistent in their reports of gender differences in aphasia incidence rate or severity (Hier et al., 1994; Pedersen et al., 1995; Pizzamiglio et al., 1985; Kertesz and Sheppard, 1981; Engelter et al., 2006; Flowers et al., 2013; Kadojić et al., 2012; Bersano et al., 2009). One reason for this could be that unselected stroke patient groups often have a different age distribution for the two genders, due to the longer lifespan of females (Di Carlo et al., 2003; Kelly-Hayes et al., 2003). A recent meta-analysis (Wallentin, 2018), including 25 studies and a total of 48,362 stroke patients found a consistently higher prevalence of aphasia in female stroke patients than in male, uncorrected for age. Further, in the 
same paper Wallentin conducted an analysis of data from a large US patient database with $1,900,000$ stroke patients and found the same overrepresentation of women among aphasia patients. However, when including a correction for age differences, the gender difference was no longer significant (see figure 6). This finding speaks against the notion that women have less lateralized language function. If that were true, women would be less vulnerable to post-stroke aphasia, under the assumptions that bilaterality would be a protective factor against post-stroke aphasia, due to the fact that stroke is usually unilateral.

\section{**FIGURE 6 AROUND HERE**}

\section{Type of aphasia}

Studies investigating the relationship between gender and type of aphasia also have failed to find any consistent effects (Godefroy et al., 2002; Kertesz and Sheppard, 1981). Pedersen and coworkers (1995) studied 880 stroke patients and found no significant relationship between aphasia score and gender, nor any difference between men and women in the distribution of aphasia and anteriorposterior lesion localization.

\section{Aphasia recovery}

Most studies (Inatomi et al., 2008; Lendrem and Lincoln, 1985; Pedersen et al., 1995; Pedersen et al., 2004) fail to find gender differences in aphasia recovery (see Watila and Balarabe, 2015 for a review), but a few find larger improvements in women (Pizzamiglio et al., 1985; Basso et al., 1982).

\section{Category specific deficits}

The functional organization of conceptual knowledge has been a central topic in cognitive neuroscience since Warrington described the first cases of selective impairments for particular semantic categories in patients with brain injury (Warrington and McCarthy, 1987; Warrington and Shallice, 1984; Warrington, 1975). It was initially found that comprehension of artefacts could be relatively preserved compared with comprehension of biological entities and vice versa. Other subdivisions of category specific impairments have also been suggested, e.g. within the category of biological entities, it has been found that brain injury can disproportionately disrupt the processing of fruit and vegetable concepts relative to animals (Capitani et al., 2009). 
In the past decades there have also been reports of gender differences in these category specific deficits. In a review of single case studies (Gainotti, 2010) it was found that $70 \%$ of patients with category specific impairments were male, while only 30\% were female. Furthermore, it was observed that 20 out of $21(95 \%)$ patients with a greater impairment for fruit and vegetables were males, whereas 9 out of $11(80 \%)$ patients with a predominant impairment for animals were females.

However, if these gender differences were to have an evolutionary origin, one would expect them to be present in a healthy population of young individuals raised in a society with a large degree of gender equality. Contrary to this, no evidence of gender differences in category-specificity was found in a relatively large sample $(\mathrm{N}>350)$ drawn from such a population (Gerlach and Gainotti, 2016). Gender differences in semantic processing and deficits may thus reflect differences in familiarity with particular semantic categories, originating in gender roles or gendered interests, as we saw play out with word-use (see above).

\section{Psychiatric disorders}

\section{Depression}

The prevalence, incidence and morbidity risk of depressive disorders are higher in females than in males, beginning at mid-puberty and persisting through adult life (Parker and Brotchie, 2010; Piccinelli and Wilkinson, 2000). The diagnosis of depression (American Psychiatric Association, 2013) crucially depends on subjective report, i.e. language. The symptoms that can be observed without a verbal report, such as weight change or sleep disturbances, are not sufficient to diagnose a depressive episode (Bagby et al., 2004; Bech et al., 1975).

Language use on social media has been found to be predictive of depression (Eichstaedt et al., 2018). Language-derived personality and demographic estimates show strong performance in distinguishing users that disclose a diagnosis of depression on the social media platform Twitter from random controls users of the platform (Preotiuc-Pietro et al., 2015). Adding gender (estimated from language use) to the model was found to significantly improve prediction of depression. One aspect of depression is an increased self-focus and perseveration on self-relevant information 
(Pyszczynski and Greenberg, 1987). In line with this, a meta-analysis found that across different types of language production tasks, depression was linked to an increased use of first-person pronouns (Edwards and Holtzman, 2017; Eichstaedt et al., 2018). The effect size was small $(\mathrm{r}=0.13)$, but higher than other linguistic correlates of personality traits (Edwards and Holtzman, 2017). Prior to a suicide attempt, Twitter users also present more self-focused language (Coppersmith et al., 2016). It is impossible not to speculate on the connection between these findings and the fact that women both have more frequent use of $1^{\text {st }}$ person pronouns (see above) and greater depression rates. Edward \& Holtzman, however, did not find any moderation of the correlation between pronoun use and depression by gender, although it was nominally higher in females. A possible link, though, is through neuroticism, a personality trait known to increase the risk for depression and be more frequent in females (Fanous et al., 2002; Goodwin and Gotlib, 2004) and also linked to increased use of $1^{\text {st }}$ person pronouns (Schwartz et al., 2013). Again, it seems that on a population basis, the gender difference in mood-related self-centering and the accompanying use of $1^{\text {st }}$ person pronouns is negligible (small effect size), but when only looking at the tail of the distribution, where mood and word-use may turn into a vicious cycle, females outnumber males. Again, we have no brain correlates of depression as a categorical diagnosis, perhaps because it is simply the tail of a normal distribution.

\section{Schizophrenia}

The origin of schizophrenia has speculatively been linked to both sex and language. It has been suggested to be "the price that Homo sapiens pays for language" (Crow, 1997), the idea being that schizophrenia is a side-product of language evolution, tied to brain lateralization which again supposedly relies on the sex chromosomes. There is some evidence that schizophrenia is linked to smaller degrees of lateralization (Sommer et al., 2001; Bleich-Cohen et al., 2009; Somers et al., 2009), but this has not convincingly been tied to gender differences (Sommer et al., 2003). There are, however, multiple other observed gender differences in the symptomatology of schizophrenia (e.g. Falkenburg and Tracy, 2014; Mendrek and Mancini-Marïe, 2016). Here, I will focus on symptoms linked to language.

Hallucinations are among the defining characteristics of schizophrenia. Auditory hallucinations, most often in the shape of voices, are the most common form of hallucinations in schizophrenia and 
related disorders (American Psychiatric Association, 2013). Auditory hallucinations are experienced by around $60 \%$ of all patients diagnosed with a schizophrenia spectrum disorder (Waters et al., 2014). While auditory verbal hallucinations (AVH) are in themselves linguistic phenomena, the science of AVHs is further complicated by the fact that they can only be studied by verbal report. The tendency in the population to hear voices is probably distributed along a continuum (Strauss, 1969; van Os et al., 2000; Johns et al., 2014), and depending on how the question is asked, studies find that between $0.6 \%$ and $84 \%$ of the population (median: $13.2 \%$ ) has experienced AVHs (Beavan et al., 2011). One theory is that AVHs are our own inner voice which is misinterpreted as belonging to somebody else (Moseley et al., 2013; Frith, 1992).

It has been reported that women in the normal population more often hear voices than men, with reports estimating a 50\% higher prevalence in women. (Murphy et al., 2010; Tien, 1991; Dolphin et al., 2015) with some cultural differences (Johns et al., 2002). A similar difference has been found in schizophrenia patient samples (Rector and Seeman, 1992; Marneros, 1984). However, representative population samples of normal 7-8 year old children (Bartels-Velthuis et al., 2010), as well as 11-12 year old (Yoshizumi et al., 2004), found no gender difference in AVHs. Studies of overall prevalence of hallucinations (both auditory and others) have also failed to find gender differences (Scott et al., 2009). A recent population study on adults also failed to find a significant gender difference in the frequency of hearing voices (Kråkvik et al., 2015). Overall, these findings make it difficult to affirm of disconfirm the presence of gender differences in AVHs, but if they exist, their effect size may not be as large as previously thought.

Interestingly, the most dominant voice heard by psychotic patients with AVHs is usually male (70\%), both for women and men (Nayani and David, 1996).

Gender differences in overall language function in schizophrenia patients have also been found with men reported to perform worse than women (Walder et al., 2006; DeLisi, 2001; Bozikas et al., 2010). Other studies, however, have found other and/or more general cognitive deficits in men, not linked to language in particular (Goldstein et al., 1998; Han et al., 2012). Yet others find no effect (Goldberg et al., 1995). Thus, although language plays a central role in schizophrenia, no clear picture has emerged on gender differences in language-related symptoms. 


\section{Summary and synthesis}

Language plays a huge role in human life and as a consequence also in development and brain function. Gender and sex differences in language can be signs of deeper cognitive differences, but may also be the primary cause for them.

Three models for gender differences were presented: strongly innate differences linked to genetic sex, cultural gender difference linked to environmental asymmetries and interaction accounts in which non-linguistic differences influence language function.

The only example of a clearly innate language effect linked to sex is the difference in voice quality. The development of differences in fundamental frequency of male and female voices is under strong genetic and hormonal control, and the result is two more or less completely separate distributions, allowing precise classification of sex on the basis of very small speech segments.

The remaining observations of gender differences in language all belong to the other two models.

There is very little evidence for the hypothesis that females are inherently more "expressive" than males, given that both genders use a similar amount of words, although they often use them to talk about different things and in a slightly different manner. The general picture from development is that girls and women have a slight linguistic advantage to boys and men, but gender as a categorical variable explains very little of the variance in linguistic proficiency seen across the population, with effect sizes usually in the small range. Males, however, outnumber females among the lowest scoring percentiles in language tests (approximately 2:1), and since certain developmental deficits arise from a poorly functioning language (including developmental language disorder, dyslexia, stuttering and autism), males also clearly outnumber females in these diagnoses.

This leads to a situation where your perspective on gender differences in language determines the conclusion. If you focus on the population as a whole, gender differences in language are negligible, but if you focus on the parts of the population with developmental language deficits, gender differences are real and tangible. As of yet, no neural correlates have been found for these disorders, even though they are highly heritable; perhaps because developmental language deficits are simply the tails of the normal spectrum rather than categorical deficits. 
There is no support in the literature for the hypothesis that males and females differ on large-scale functional brain systems for language. No difference in lateralization is found in meta-analyses on neuroimaging studies of language processing, and while post-stroke aphasia is more prevalent among females than males, this effect seems to be an age confound rather than a gender effect because on average, women are older at age of stroke. Language related symptoms in neurodegenerative disorders, such as Huntington's disease, Parkinson's disease and dementias, also show no consistent gender differences.

Differences in word-use can be observed among the genders, making it possible to decode gender on this basis with a high degree of certainty. The two genders apparently have diverging interests, and this is reflected in language use. It is an open question if this is due to innate and/or cultural differences. One of the interesting findings is that women use more $1^{\text {st }}$ person pronouns. The same phenomenon is observed in depression and given that women more often get diagnosed with depression, there might be a link. This needs to be investigated further. Again, it seems that the overall effect size is small, but there may be reasons that cause females to outnumber males in the tail of the distribution.

Across sex chromosome trisomies, language is affected to a larger degree than other cognitive functions. Thus, it is not the underlying phenotypical gender, but rather the presence of an added chromosome that seems to be dispositive for the primary effect, although some evidence points to a larger impact of an additional Y chromosome than of an X. It thus seems that adding an extra chromosome is one way in which people are pushed towards the lowest percentiles of the language proficiency distribution. However, many other unfortunate combinations of genes may trigger vulnerability to language deficits, with each gene only contributing with a very small effect. Only a minority of these will be related to sex.

The same logic applies to environmental effects. Most likely, there are a multitude of reasons for boys enjoying reading less than girls on average, and this can lead to diverse effects on language skills in general, depending on whether boys chose to replace reading with other languagesupporting activities. 
Future work should aim at studying the dynamic processes during development where language plays a role and where early gender differences might send a subset of boys and girls out on divergent linguistic trajectories. Likewise, it is worth considering if the role language plays in psychiatric disorders can somehow be altered by linguistic interventions. Psychotherapy is often a type of linguistic intervention, but other interventions specifically countering maladaptive linguistic behavior, such as self-centered inner and outer voices and speech, could be considered as well. The impact of such an intervention may turn out to show a gender difference. 


\section{References}

Abou Ella M, Saleh M, Habil I, et al. (2015). Prevalence of stuttering in primary school children in Cairo-Egypt. Int J Speech Lang Pathol 17: 367-372.

Acarlar F, Aksu-Koç A, Küntay AC, et al. (2009). Adapting MB-CDI to Turkish: The first phase. In: Ay S, Aydın. Ö, Ergenç I, et al. (eds.) Essays on Turkish linguistics: Proceedings of the 14th International Conference on Turkish Linguistics, August 6-8, 2008. Wiesbaden: Harrassowitz Verlag.

Acheson DJ, Wells JB \& MacDonald MC (2008). New and updated tests of print exposure and reading abilities in college students. Behav Res Methods 40: 278-289.

Akhavan Karbasi S, Fallah R \& Golestan M (2011). The Prevalence of Speech Disorder in Primary School Students in Yazd-Iran. Acta Med Iran 49: 33-37.

American Psychiatric Association (2013). Diagnostic and statistical manual of mental disorders (DSM-5), Washington DC, American Psychiatric Publishing.

Ardila A, Bateman J, Niño CR, et al. (1994). An epidemiologic study of stuttering. J Commun Disord 27: 37-48.

Autism and Developmental Disabilities Monitoring Network Surveillance Year 2010 Principal Investigators (2014). Prevalence of Autism Spectrum Disorder Among Children Aged 8 Years - Autism and Developmental Disabilities Monitoring Network, 11 Sites, United States, 2010. Morb Mortal Wkly Rep Surveill Summ 63: 1-21.

Bachorowski J-A \& Owren MJ (1999). Acoustic correlates of talker sex and individual talker identity are present in a short vowel segment produced in running speech. J Acoust Soc Am 106: 1054-1063.

Bagby RM, Ryder AG, Schuller DR, et al. (2004). The Hamilton Depression Rating Scale: has the gold standard become a lead weight? Am J Psychiatry 161: 2163-2177.

Bailey A, Le Couteur A, Gottesman I, et al. (1995). Autism as a strongly genetic disorder: evidence from a British twin study. Psychol Med 25: 63-77.

Bardsley MZ, Kowal K, Levy C, et al. (2013). 47,XYY Syndrome: Clinical Phenotype and Timing of Ascertainment. J Pediatr 163: 1085-1094.

Baron-Cohen S, Knickmeyer RC \& Belmonte MK (2005). Sex Differences in the Brain: Implications for Explaining Autism. Science 310: 819-823.

Barry D, Bates ME \& Labouvie E (2008). FAS and CFL Forms of Verbal Fluency Differ in Difficulty: A Meta-analytic Study. Appl Neuropsychol 15: 97-106.

Bartels-Velthuis AA, Jenner JA, van de Willige G, et al. (2010). Prevalence and correlates of auditory vocal hallucinations in middle childhood. Br J Psychiatry 196: 41-46.

Basile A, Dwyer G, Medvedeva M, et al. Simply the Best: Minimalist System Trumps Complex Models in Author Profiling. In: Bellot P, Trabelsi C, Mothe J, et al., eds. Experimental IR Meets Multilinguality, Multimodality, and Interaction, 2018// 2018 Cham. Springer, 143156.

Basso A, Capitani E \& Moraschini S (1982). Sex Differences in Recovery from Aphasia. Cortex 18: 469-475.

Beach J, Brownlow S, Greene M, et al. (2016). The "I"s have it: Sex and social status differences on Twitter. Soc Behav Res Practice 1: 17-21.

Beavan V, Read J \& Cartwright C (2011). The prevalence of voice-hearers in the general population: A literature review. J Ment Health 20: 281-292.

Bech P, Gram LF, Dein E, et al. (1975). Quantitative rating of depressive states. Acta Psychiatr Scand 51: 161-170. 
Beitchman JH, Wilson B, Johnson CJ, et al. (2001). Fourteen-Year Follow-up of Speech/LanguageImpaired and Control Children: Psychiatric Outcome. J Am Acad Child Adolesc Psychiatry 40: 75-82.

Bendel J, Palti H, Winter S, et al. (1989). Prevalence of disabilities in a national sample of 3-yearold Israeli children. Isr J Med Sci 25: 264-270.

Bender BG, Puck MH, Salbenblatt JA, et al. (1986). Dyslexia in 47,XXXY boys identified at birth. Behav Genet 16: 343-354.

Berglund E, Eriksson M \& Westerlund M (2005). Communicative skills in relation to gender, birth order, childcare and socioeconomic status in 18-month-old children. Scand J Psychol 46: 485-491.

Bersano A, Burgio F, Gattinoni M, et al. (2009). Aphasia Burden to Hospitalised Acute Stroke Patients: Need for an Early Rehabilitation Programme. Int J Stroke 4: 443-447.

Bishop DVM (2010). Overlaps Between Autism and Language Impairment: Phenomimicry or Shared Etiology? Behav Genet 40: 618-629.

Bishop DVM, Jacobs PA, Lachlan K, et al. (2009). Autism, language and communication in children with sex chromosome trisomies. Arch Dis Child 96: 954.

Bishop DVM, North T \& Donlan C (1995). Genetic basis of specific language impairment: Evidence from a twin study. Dev Med Child Neurol 37: 56-71.

Bishop DVM \& Scerif G (2011). Klinefelter syndrome as a window on the aetiology of language and communication impairments in children: the neuroligin-neurexin hypothesis. Acta Paediatr 100: 903-907.

Bleich-Cohen M, Hendler T, Kotler M, et al. (2009). Reduced language lateralization in firstepisode schizophrenia: An fMRI index of functional asymmetry. Psychiatry Res Neuroimaging 171: 82-93.

Bleses D, Vach W, Slott M, et al. (2008). The Danish Communicative Developmental Inventories: validity and main developmental trends. J Child Lang 35: 1-19.

Boone KB, Swerdloff RS, Miller BL, et al. (2001). Neuropsychological profiles of adults with Klinefelter syndrome. J Int Neuropsychol Soc 7: 446-456.

Bornstein MH (2004). Specific and general language performance across early childhood: Stability and gender considerations. First Lang 24: 267-304.

Bozikas VP, Kosmidis MH, Peltekis A, et al. (2010). Sex differences in neuropsychological functioning among schizophrenia patients. Aust N Z J Psychiatry 44: 333-341.

Bruining H, Swaab H, Kas M, et al. (2009). Psychiatric Characteristics in a Self-Selected Sample of Boys With Klinefelter Syndrome. Pediatrics.

Buss AR (1976). Galton and sex differences: An historical note. J Hist Behav Sci 12: 283-285.

Buss DM \& Schmitt DP (1993). Sexual strategies theory: an evolutionary perspective on human mating. Psychol Rev 100: 204-232.

Cahill L (2006). Why sex matters for neuroscience. Nat Rev Neurosci 7: 477-484.

Capitani E, Laiacona M, Pagani R, et al. (2009). Posterior cerebral artery infarcts and semantic category dissociations: a study of 28 patients. Brain 132: 965-981.

Caro DH \& Biecek P (2017). intsvy: An R Package for Analyzing International Large-Scale Assessment Data. J Stat Softw 81: 1-44.

Caselli MC, Bates E, Casadio P, et al. (1995). A cross-linguistic study of early lexical development. Cogn Dev 10: 159-199.

Cejka MA \& Eagly AH (1999). Gender-Stereotypic Images of Occupations Correspond to the Sex Segregation of Employment. Pers Soc Psychol Bull 25: 413-423.

Cheng N, Chandramouli R \& Subbalakshmi KP (2011). Author gender identification from text. Digit Invest 8: 78-88. 
Childers DG \& Wu K (1991). Gender recognition from speech. Part II: Fine analysis. J Acoust Soc Am 90: 1841-1856.

Chow JC, Ekholm E \& Coleman H (2018). Does oral language underpin the development of later behavior problems? A longitudinal meta-analysis. Sch Psychol Q 33: 337-349.

Ciot M, Sonderegger M \& Ruths D Gender Inference of Twitter Users in Non-English Contexts. Proceedings of the 2013 Conference on Empirical Methods in Natural Language Processing, 18-21 October 20132013 Seattle.

Clarke TK, Lupton MK, Fernandez-Pujals AM, et al. (2015). Common polygenic risk for autism spectrum disorder (ASD) is associated with cognitive ability in the general population. Mol Psychiatry 21: 419.

Combs HL, Folley BS, Berry DTR, et al. (2015). Cognition and Depression Following Deep Brain Stimulation of the Subthalamic Nucleus and Globus Pallidus Pars Internus in Parkinson's Disease: A Meta-Analysis. Neuropsychol Rev 25: 439-454.

Conti-Ramsden G \& Botting N (2008). Emotional health in adolescents with and without a history of specific language impairment (SLI). J Child Psychol Psychiatry 49: 516-525.

Coppersmith G, Ngo K, Leary R, et al. Exploratory Analysis of Social Media Prior to a Suicide Attempt. Proceedings of the 3rd Workshop on Computational Linguistics and Clinical Psychology: From Linguistic Signal to Clinical Reality, 2016 San Diego. Association for Computational Linguistics, 106-117.

Craig A, Hancock K, Tran Y, et al. (2002). Epidemiology of Stuttering in the Community Across the Entire Life Span. J Speech Lang Hear Res 45: 1097-1105.

Crichton-Browne $\mathrm{J}$ (1879). On the weight of the brain and its component parts in the insane. Brain 2: 42-67.

Crow TJ (1997). Is schizophrenia the price that Homo sapiens pays for language? Schizophr Res 28: 127-141.

Cunningham AE \& Stanovich KE (1991). Tracking the Unique Effects of Print Exposure in Children: Associations With Vocabulary, General Knowledge, and Spelling. J Educ Psychol 83: 264-274.

Dale PS, Harlaar N, Hayiou-Thomas ME, et al. (2010). The Etiology of Diverse Receptive Language Skills at 12 Years. J Speech Lang Hear Res 53: 982-992.

Darwin C (1889). The descent of man, and selection in relation to sex, New York, D. Appleton and Company.

DeLisi LE (2001). Speech Disorder in Schizophrenia: Review of the Literature and Exploration of Its Relation to the Uniquely Human Capacity for Language. Schizophr Bull 27: 481-496.

Denmark FL, Klara M, Baron E, et al. (2008). Historical Development of the Psychology of Women. In: Denmark FL \& Paludi MA (eds.) Psychology of women: A handbook of Issues and theories. 2nd edition ed.: Praeger Publishers.

Deuschl G, Schade-Brittinger C, Krack P, et al. (2006). A Randomized Trial of Deep-Brain Stimulation for Parkinson's Disease. N Engl J Med 355: 896-908.

Di Carlo A, Lamassa M, Baldereschi M, et al. (2003). Sex Differences in the Clinical Presentation, Resource Use, and 3-Month Outcome of Acute Stroke in Europe. Stroke 34: 1114.

Dolphin L, Dooley B \& Fitzgerald A (2015). Prevalence and correlates of psychotic like experiences in a nationally representative community sample of adolescents in Ireland. Schizophr Res 169: 241-247.

Dworzynski K, Remington A, Rijsdijk Fh, et al. (2007). Genetic Etiology in Cases of Recovered and Persistent Stuttering in an Unselected, Longitudinal Sample of Young Twins. Am J Speech Lang Pathol 16: 169-178. 
Edwards TM \& Holtzman NS (2017). A meta-analysis of correlations between depression and first person singular pronoun use. J Res Pers 68: 63-68.

Eichstaedt JC, Smith RJ, Merchant RM, et al. (2018). Facebook language predicts depression in medical records. Proceedings of the National Academy of Sciences 115: 11203.

Elgh E, Domellöf M, Linder J, et al. (2009). Cognitive function in early Parkinson's disease: a population-based study. Eur J Neurol 16: 1278-1284.

Engelter ST, Gostynski M, Papa S, et al. (2006). Epidemiology of Aphasia Attributable to First Ischemic Stroke. Stroke 37: 1379.

Eriksson M \& Berglund E (2002). Instruments, scoring manual and percentile levels of the Swedish Early Communicative Development Inventory, SECDI. (FoU-Rapport 17), Gävle, Sweden, Institutionen för pedagogik, didaktik och psykologi.

Eriksson M, Marschik PB, Tulviste T, et al. (2011). Differences between girls and boys in emerging language skills: Evidence from 10 language communities. Br J Dev Psychol 30: 326-343.

Fairweather H (1982). Sex differences: Little reason for females to play midfield. In: Beaumont JG (ed.) Divided visual field studies of cerebral organisation. London: Academic Press.

Falkenburg J \& Tracy DK (2014). Sex and schizophrenia: a review of gender differences. Psychosis 6: 61-69.

Fanous A, Gardner CO, Prescott CA, et al. (2002). Neuroticism, major depression and gender: a population-based twin study. Psychol Med 32: 719-728.

Feinberg DR, DeBruine LM, Jones BC, et al. (2008). The Role of Femininity and Averageness of Voice Pitch in Aesthetic Judgments of Women's Voices. Perception 37: 615-623.

Feinberg DR, Jones BC, Law Smith MJ, et al. (2006). Menstrual cycle, trait estrogen level, and masculinity preferences in the human voice. Horm Behav 49: 215-222.

Fenson L, Dale PS, Reznick JS, et al. (1994). Variability in early communicative development. Monogr Soc Res Child Dev 59: 1-173; discussion 174-185.

Fenson L, Marchman VA, Thal D, et al. (2007). MacArthur-Bates Communicative Development Inventories: User's Guide and Technical Manual., Baltimore, MD, Brookes Publishing Co.

Flowers HL, Silver FL, Fang J, et al. (2013). The incidence, co-occurrence, and predictors of dysphagia, dysarthria, and aphasia after first-ever acute ischemic stroke. J Commun Disord 46: 238-248.

Flynn JR (1998). Israeli military IQ tests: Gender Differences small; IQ gains large. J Biosoc Sci 30: 541-553.

Frith CD (1992). The Cognitive Neuropsychology of Schizophrenia, Hove, Lawrence Erlbaum Associates, Publishers.

Frota S, Butler J, Correia S, et al. (2016). Infant communicative development assessed with the European Portuguese MacArthur-Bates Communicative Development Inventories short forms. First Lang 36: 525-545.

Fusaroli R, Lambrechts A, Bang D, et al. (2016). "Is voice a marker for Autism spectrum disorder? A systematic review and meta-analysis". Autism Res 10: 384-407.

Gainotti G (2010). The influence of anatomical locus of lesion and of gender-related familiarity factors in category-specific semantic disorders for animals, fruits and vegetables: A review of single-case studies. Cortex 46: 1072-1087.

Galton F (1892). Inquiries into Human Faculty and its Development, London, MacMillan.

Gerlach C \& Gainotti G (2016). Gender differences in category-specificity do not reflect innate dispositions. Cortex 85: 46-53.

Gerlach H, Totty E, Subramanian A, et al. (2018). Stuttering and Labor Market Outcomes in the United States. J Speech Lang Hear Res 61: 1649-1663. 
Geschwind N \& Galaburda AM (1985). Cerebral lateralization: Biological mechanisms, associations, and pathology: i. a hypothesis and a program for research. Arch Neurol 42: 428-459.

Godefroy O, Dubois C, Debachy B, et al. (2002). Vascular Aphasias. Main Characteristics of Patients Hospitalized in Acute Stroke Units. Stroke 33: 702.

Goldberg TE, Gold JM, Torrey EF, et al. (1995). Lack of sex differences in the neuropsychological performance of patients with schizophrenia. Am J Psychiatry 152: 883-888.

Goldstein JM, Seidman LJ, Goodman JM, et al. (1998). Are There Sex Differences in Neuropsychological Functions Among Patients With Schizophrenia? Am J Psychiatry 155: 1358-1364.

Goodwin RD \& Gotlib IH (2004). Gender differences in depression: the role of personality factors. Psychiatry Res 126: 135-142.

Gravholt CH, Chang S, Wallentin M, et al. (2018). Klinefelter Syndrome: Integrating Genetics, Neuropsychology, and Endocrinology. Endocr Rev 39: 389-423.

Gray H (1918). Anatomy of the human body, Philidelphia, Lea \& Febiger.

Grossman M (2010). Primary progressive aphasia: clinicopathological correlations. Nat Rev Neurol 6: 88 .

Haines EL, Deaux K \& Lofaro N (2016). The Times They Are a-Changing ... or Are They Not? A Comparison of Gender Stereotypes, 1983-2014. Psychol Women Q 40: 353-363.

Hammill DD, Brown VL, Larsen SC, et al. (1994). Test of Adolescent and Adult Language (TOAL-3), Austin, TX Pro-Ed.

Han M, Huang X-F, Chen DC, et al. (2012). Gender differences in cognitive function of patients with chronic schizophrenia. Prog Neuropsychopharmacol Biol Psychiatry 39: 358-363.

Harries MLL, Walker JM, Williams DM, et al. (1997). Changes in the male voice at puberty. Arch Dis Child 77: 445.

Harris LJ (1978). Sex differences in spatial ability: Possible environmental, genetic, and neurological factors. In: Kinsbourne M (ed.) Assymetrical function of the brain. Cambridge: Cambridge University Press.

Haslam N, Rothschild L \& Ernst D (2000). Essentialist beliefs about social categories. Br J Soc Psychol 39: 113-127.

Hayiou-Thomas ME, Dale PS \& Plomin R (2012). The etiology of variation in language skills changes with development: a longitudinal twin study of language from 2 to 12 years. Dev Sci 15: 233-249.

Henry JD, Crawford JR \& Phillips LH (2004). Verbal fluency performance in dementia of the Alzheimer's type: a meta-analysis. Neuropsychologia 42: 1212-1222.

Hier DB, Yoon WB, Mohr JP, et al. (1994). Gender and Aphasia in the Stroke Data Bank. Brain Lang 47: 155-167.

Hirnstein M, Hugdahl K \& Hausmann M (2018). Cognitive sex differences and hemispheric asymmetry: A critical review of 40 years of research. Laterality: 1-49.

Hirnstein M, Westerhausen R, Korsnes MS, et al. (2013). Sex differences in language asymmetry are age-dependent and small: A large-scale, consonant-vowel dichotic listening study with behavioral and fMRI data. Cortex 49: 1910-1921.

Hodges JR \& Patterson K (2007). Semantic dementia: a unique clinicopathological syndrome. Lancet Neurol 6: 1004-1014.

Højlund A, Petersen MV, Sridharan KS, et al. (2017). Worsening of Verbal Fluency After Deep Brain Stimulation in Parkinson's Disease: A Focused Review. Comput Struct Biotechnol J 15: 68-74. 
Hong DS \& Reiss AL (2014). Cognitive and neurological aspects of sex chromosome aneuploidies. Lancet Neurol 13: 306-318.

Howie PM (1981). Concordance for Stuttering in Monozygotic and Dizygotic Twin Pairs. J Speech Lang Hear Res 24: 317-321.

Hughes SM, Dispenza F \& Gallup GG (2004). Ratings of voice attractiveness predict sexual behavior and body configuration. Evol Hum Behav 25: 295-304.

Hyde JS (2005). The Gender Similarities Hypothesis. Am Psychol 60: 581-592.

Hyde JS (2014). Gender similarities and differences. Annu Rev Psychol 65: 373-398.

Hyde JS \& Linn MC (1988). Gender Differences in Verbal Ability: A Meta-Analysis. Psychol Bull 104: 53-69.

Im-Bolter N \& Cohen NJ (2007). Language Impairment and Psychiatric Comorbidities. Pediatr Clin North Am 54: 525-542.

Inatomi Y, Yonehara T, Omiya S, et al. (2008). Aphasia during the acute phase in ischemic stroke. Cerebrovasc Dis 25: 316-323.

Jackson-Maldonado D, Thal D, Marchman V, et al. (2003). MacArthur Inventarios del Desarrollo de Habilidades Comunicativas. User's Guide and Technical Manual., Baltimore, MD, Brookes Publishing Co.

Jiang H, Logan JA \& Jia R (2018). Modeling the Nature of Grammar and Vocabulary Trajectories From Prekindergarten to Third Grade. J Speech Lang Hear Res 61: 910-923.

Johns LC, Kompus K, Connell M, et al. (2014). Auditory Verbal Hallucinations in Persons With and Without a Need for Care. Schizophr Bull 40: S255-S264.

Johns LC, Nazroo JY, Bebbington P, et al. (2002). Occurrence of hallucinatory experiences in a community sample and ethnic variations. Br J Psychiatry 180: 174-178.

Jones EJH, Gliga T, Bedford R, et al. (2014). Developmental pathways to autism: A review of prospective studies of infants at risk. Neurosci Biobehav Rev 39: 1-33.

Kadojić D, Rostohar Bijelić B, Radanović R, et al. (2012). Aphasia in Patients with Ischemic Stroke. Acta Clin Croat 51: 221-224.

Kaiser A, Haller S, Schmitz S, et al. (2009). On sex/gender related similarities and differences in fMRI language research. Brain Res Rev.

Kalashnikova M, Schwarz I-C \& Burnham D (2016). OZI: Australian English Communicative Development Inventory. First Lang 36: 407-427.

Kansaku K, Yamaura A \& Kitazawa S (2000). Sex Differences in Lateralization Revealed in the Posterior Language Areas. Cereb Cortex 10: 866-872.

Kefalianos E, Onslow M, Ukoumunne O, et al. (2014). Stuttering, Temperament, and Anxiety: Data From a Community Cohort Ages 2-4 Years. J Speech Lang Hear Res 57: 1314-1322.

Kelly-Hayes M, Beiser A, Kase CS, et al. (2003). The influence of gender and age on disability following ischemic stroke: the Framingham study. J Stroke Cerebrovasc Dis 12: 119-126.

Kertesz A \& Sheppard ANN (1981). The Epidemiology of Aphasic and Cognitive impairment in Stroke: Age, Sex, Aphasia Type and Laterality Differences. Brain 104: 117-128.

Kimura D (2004). Human sex differences in cognition, fact, not predicament. Sex Evol Gend. 6: 4553.

Kite ME, Deaux K \& Haines EL (2008). Gender stereotypes. In: Denmark FL \& Paludi MA (eds.) Psychology of women: A handbook of issues and theories. 2nd edition ed. Westport, Conneticut: Praeger.

Klimova B \& Kuca K (2016). Speech and language impairments in dementia. J Appl Biomed 14: 97-103. 
Kovacevic M, Babic Z \& Brozovic B A Croatian language parent report study: Lexical and grammatical development. VIIth International Congress for the Study of Child Language, 1996 Istanbul, Turkey.

Kråkvik B, Larøi F, Kalhovde AM, et al. (2015). Prevalence of auditory verbal hallucinations in a general population: A group comparison study. Scand J Psychol 56: 508-515.

Lam JMC \& Wodchis WP (2010). The Relationship of 60 Disease Diagnoses and 15 Conditions to Preference-Based Health-Related Quality of Life in Ontario Hospital-Based Long-Term Care Residents. Med Care 48: 380-387.

Lange BP, Zaretsky E, Schwarz S, et al. (2014). Words Won't Fail: Experimental Evidence on the Role of Verbal Proficiency in Mate Choice. J Lang Soc Psychol 33: 482-499.

Laws KR, Duncan A \& Gale TM (2010). 'Normal' semantic-phonemic fluency discrepancy in Alzheimer's disease? A meta-analytic study. Cortex 46: 595-601.

Leaper C \& Ayres MM (2007). A Meta-Analytic Review of Gender Variations in Adults' Language Use: Talkativeness, Affiliative Speech, and Assertive Speech. Pers Soc Psychol Rev 11: 328-363.

Leaper C \& Robnett RD (2011). Women Are More Likely Than Men to Use Tentative Language, Aren't They? A Meta-Analysis Testing for Gender Differences and Moderators. Psychol Women Q 35: 129-142.

Lee NR, Wallace GL, Adeyemi EI, et al. (2012). Dosage effects of X and Y chromosomes on language and social functioning in children with supernumerary sex chromosome aneuploidies: implications for idiopathic language impairment and autism spectrum disorders. J Child Psychol Psychiatry 53: 1072-1081.

Lendrem W \& Lincoln NB (1985). Spontaneous recovery of language in patients with aphasia between 4 and 34 weeks after stroke. J Neurol Neurosurg Psychiatry 48: 743.

Levinson SC (2003). Space in Language and Cognition, Cambridge, Cambridge University Press.

Levy J \& Reid M (1978). Variations in cerebral organization as a function of handedness, hand posture in writing, and sex. J Exp Psychol Gen 107: 119-144.

Lewis BA \& Thompson LA (1992). A Study of Developmental Speech and Language Disorders in Twins. J Speech Lang Hear Res 35: 1086-1094.

Locke JL \& Bogin B (2006). Language and life history: A new perspective on the development and evolution of human language. Behav Brain Sci 29: 259-280.

López Ornat S, Gallego C, Gallo P, et al. (2005). MacArthur: Inventario de desarrollo comunicativo. Manual y Cuadernillos., Madrid, TEA Ediciones.

Lundberg I, Larsman P \& Strid A (2012). Development of phonological awareness during the preschool year: the influence of gender and socio-economic status. Read Writ 25: 305-320.

Lundberg I, Olofsson $\AA \&$ Wall S (1980). Reading and spelling skills in the first school years predicted from phonemic awareness skills in kindergarten. Scand J Psychol 21: 159-173.

Lynn R \& Mikk J (2009). Sex differences in reading achievement. TRAMES-J Humanit Soc 13: 313.

MacLarnon AM \& Hewitt GP (1999). The evolution of human speech: The role of enhanced breathing control. Am J Phys Anthropol 109: 341-363.

Maier M \& Abdel Rahman R (2018). Native Language Promotes Access to Visual Consciousness. Psychol Sci: 0956797618782181.

Månson H (2005). Stammens kompleksitet og diversitet. Dansk Audiologopaedi 41: 13-33.

Markova D, Richer L, Pangelinan M, et al. (2016). Age- and sex-related variations in vocal-tract morphology and voice acoustics during adolescence. Horm Behav 81: 84-96.

Markova G \& Smolík F (2013). What Do You Think? The Relationship between Person Reference and Communication About the Mind in Toddlers. Soc Dev 23: 61-79. 
Marlowe FW (2007). Hunting and Gathering: The Human Sexual Division of Foraging Labor. Cross Cult Res 41: 170-195.

Marneros A (1984). Frequency of occurrence of Schneider's first rank symptoms in schizophrenia. Eur Arch Psychiatry Neurol Sci 234: 78-82.

McAllister J, Collier J \& Shepstone L (2012). The impact of adolescent stuttering on educational and employment outcomes: Evidence from a birth cohort study. J Fluency Disord 37: 106121.

McCulloch JW \& Fawcett PG (1964). Some Factors Affecting the Prevalence of Stammering. Br J Prev Soc Med 18: 146-151.

McGlone J (1980). Sex differences in human brain asymmetry: a critical survey. Behav Brain Sci 3: 215-263.

McKinnon DH, McLeod S \& Reilly S (2007). The Prevalence of Stuttering, Voice, and SpeechSound Disorders in Primary School Students in Australia. Lang Speech Hear Serv Sch 38: 5-15.

Mehl MR \& Pennebaker JW (2003). The sounds of social life: A psychometric analysis of students' daily social environments and natural conversations. J Pers Soc Psychol 84: 857-870.

Mehl MR, Vazire S, Ramírez-Esparza N, et al. (2007). Are Women Really More Talkative Than Men? Science 317: 82-82.

Mendrek A \& Mancini-Marie A (2016). Sex/gender differences in the brain and cognition in schizophrenia. Neurosci Biobehav Rev 67: 57-78.

Miles TR, Haslum MN \& Wheeler TJ (1998). Gender ratio in dyslexia. Ann Dyslexia 48: 27-55.

Miller GF (2000). The Mating Mind: How Sexual Choice Shaped the Evolution of Human Nature, New York, Doubleday.

Mitchell S, Brian J, Zwaigenbaum L, et al. (2006). Early Language and Communication Development of Infants Later Diagnosed with Autism Spectrum Disorder. J Dev Behav Pediatr 27: S69-S78.

Mohamadi H, Nilipour R \& Yadegari F (2008). Stuttering Prevalence among Kurdish-Farsi Students Effects of the Two Languages Similarities. Iran Rehab J 6: 83-88.

Mohamadi O, Rahimi-Madiseh M \& Sedehi M (2016). The prevalence of stuttering, voice disorder, and speech sound disorders in preschoolers in Shahrekord, Iran. Int J Child Youth Fam Stud 7: 456-471.

Moseley P, Fernyhough C \& Ellison A (2013). Auditory verbal hallucinations as atypical inner speech monitoring, and the potential of neurostimulation as a treatment option. Neurosci Biobehav Rev 37: 2794-2805.

Murphy J, Shevlin M, Adamson G, et al. (2010). Positive psychosis symptom structure in the general population: Assessing dimensional consistency and continuity from "pathology" to "normality". Psychosis 2: 199-209.

Murphy MM (2009). Language and Literacy in Turner Syndrome. Top Lang Disord 29: 187-194.

Nayani TH \& David AS (1996). The auditory hallucination: a phenomenological survey. Psychol Med 26: 177-189.

Nenert R, Allendorfer JB, Martin AM, et al. (2017). Age-related language lateralization assessed by fMRI: The effects of sex and handedness. Brain Res 1674: 20-35.

Newman ML, Groom CJ, Handelman LD, et al. (2008). Gender Differences in Language Use: An Analysis of 14,000 Text Samples. Discourse Process 45: 211-236.

Norbury CF, Gooch D, Baird G, et al. (2016a). Younger children experience lower levels of language competence and academic progress in the first year of school: evidence from a population study. J Child Psychol Psychiatry 57: 65-73. 
Norbury CF, Gooch D, Wray C, et al. (2016b). The impact of nonverbal ability on prevalence and clinical presentation of language disorder: evidence from a population study. J Child Psychol Psychiatry 57: 1247-1257.

Ntourou K, Conture EG \& Lipsey MW (2011). Language Abilities of Children Who Stutter: A Meta-Analytical Review. Am J Speech Lang Pathol 20: 163-179.

Obeid AH, Baie HA \& Alturaihi SH (2015). Prevalence of speech disorders among elementary school children In Al-Hilla city, Iraq, 2014. Iraqi J Community Med 28: 22-27.

Obeso I, Casabona E, Bringas ML, et al. (2012). Semantic and Phonemic Verbal Fluency in Parkinson's Disease: Influence of Clinical and Demographic Variables. Behav Neurol 25.

Onyike CU \& Diehl-Schmid J (2013). The epidemiology of frontotemporal dementia. Int Rev Psychiatry 25: 130-137.

Pae S \& Kwak K (2011). Korean MacArthur-Bates Communicative Development Inventories (K M-B CDI), Seoul, Mindpress.

Parker G \& Brotchie H (2010). Gender differences in depression. Int Rev Psychiatry 22: 429-436.

Parsons TD, Rogers SA, Braaten AJ, et al. (2006). Cognitive sequelae of subthalamic nucleus deep brain stimulation in Parkinson's disease: a meta-analysis. Lancet Neurol 5: 578-588.

Pedersen PM, Jørgensen HS, Nakayama H, et al. (1995). Aphasia in acute stroke: incidence, determinants, and recovery. Ann Neurol 38: 659-666.

Pedersen PM, Vinter K \& Olsen TS (2004). Aphasia after Stroke: Type, Severity and Prognosis. Cerebrovasc Dis 17: 35-43.

Perry TL, Ohde RN \& Ashmead DH (2001). The acoustic bases for gender identification from children's voices. J Acoust Soc Am 109: 2988-2998.

Petit D, Touchette É, Tremblay RE, et al. (2007). Dyssomnias and Parasomnias in Early Childhood. Pediatrics 119: e1016.

Pfannkuche KA, Bouma A \& Groothuis TGG (2009). Does testosterone affect lateralization of brain and behaviour? A meta-analysis in humans and other animal species. Philos Trans R Soc Lond B Biol Sci 364: 929.

Phelps EA, O'Connor KJ, Gatenby JC, et al. (2001). Activation of the left amygdala to a cognitive representation of fear. Nat Neurosci 4: 437-441.

Phillips MD, Lowe MJ, Lurito JT, et al. (2001). Temporal Lobe Activation Demonstrates Sex-based Differences during Passive Listening. Radiology 220: 202-207.

Piccinelli M \& Wilkinson G (2000). Gender differences in depression: Critical review. Br J Psychiatry 177: 486-492.

Pizzamiglio L, Mammucari A \& Razzano C (1985). Evidence for sex differences in brain organization in recovery in aphasia. Brain Lang 25: 213-223.

Podoll K, Caspary P, Lange HW, et al. (1988). Language functions in Huntington's disease. Brain 111: $1475-1503$.

Porfert AR \& Rosenfield DB (1978). Prevalence of stuttering. J Neurol Neurosurg Psychiatry 41: 954.

Preotiuc-Pietro D, Eichstaedt J, Park G, et al. The Role of Personality, Age and Gender in Tweeting about Mental Illnesses. Proceedings of the 2nd Workshop on Computational Linguistics and Clinical Psychology: From Linguistic Signal to Clinical Reality, 2015 Denver. Association for Computational Linguistics, 21-30.

Proctor A, Yairi E, Duff MC, et al. (2008). Prevalence of Stuttering in African American Preschoolers. J Speech Lang Hear Res 51: 1465-1479.

Puts DA, Gaulin SJC \& Verdolini K (2006). Dominance and the evolution of sexual dimorphism in human voice pitch. Evol Hum Behav 27: 283-296. 
Pyszczynski T \& Greenberg J (1987). Self-Regulatory Perseveration and the Depressive SelfFocusing Style. Psychol Bull 102: 122-138.

Quinn JM (2018). Differential identification of females and males with reading difficulties: A metaanalysis. Read Writ 31: 1039-1061.

Rautakoski P, Hannus T, Simberg S, et al. (2012). Genetic and environmental effects on stuttering: A twin study from Finland. J Fluency Disord 37: 202-210.

Rector NA \& Seeman MV (1992). Auditory hallucinations in women and men. Schizophr Res 7: 233-236.

Regier T, Kay P \& Khetarpal N (2007). Color naming reflects optimal partitions of color space. Proc Natl Acad Sci U S A 104: 1436-1441.

Reinhardt VP, Wetherby AM, Schatschneider C, et al. (2015). Examination of Sex Differences in a Large Sample of Young Children with Autism Spectrum Disorder and Typical Development. J Autism Dev Disord 45: 697-706.

Rippon G, Jordan-Young R, Kaiser A, et al. (2014). Recommendations for sex/gender neuroimaging research: key principles and implications for research design, analysis, and interpretation. Front Hum Neurosci 8.

Roberson D, Davidoff J, Davies IRL, et al. (2005). Color categories: evidence for the cultural relativity hypothesis. Cogn Psychol 50: 378-411.

Rosenberg J \& Tunney RJ (2008). Human Vocabulary Use as Display. Evol Psychol 6: 147470490800600318.

Ross JL, Zeger MPD, Kushner H, et al. (2009). An extra X or Y chromosome: contrasting the cognitive and motor phenotypes in childhood in boys with 47, XYY syndrome or 47,XXY Klinefelter syndrome. Dev Disabil Res Rev 15: 309-317.

Rovet J, Netley C, Keenan M, et al. (1996). The Psychoeducational Profile of Boys with Klinefelter Syndrome. J Learn Disabil 29: 180-196.

Sandin S, Lichtenstein P, Kuja-Halkola R, et al. (2014). The familial risk of autism. JAMA 311: 1770-1777.

Sap M, Park G, Eichstaedt JC, et al. Developing Age and Gender Predictive Lexica over Social Media. Proceedings of the 2014 Conference on Empirical Methods in Natural Language Processing (EMNLP), October 25-29 2014 Doha, Qatar. 1146-1151.

Sarraute C, Blanc P \& Burroni J A study of age and gender seen through mobile phone usage patterns in Mexico. 2014 IEEE/ACM International Conference on Advances in Social Networks Analysis and Mining (ASONAM 2014), 2014. 836-843.

Schwartz HA, Eichstaedt JC, Kern ML, et al. (2013). Personality, gender, and age in the language of social media: the open-vocabulary approach. PLoS One 8: e73791.

Scott J, Martin G, Bor W, et al. (2009). The prevalence and correlates of hallucinations in Australian adolescents: Results from a national survey. Schizophr Res 107: 179-185.

Shaywitz BA, Shaywitz SE, Pugh KR, et al. (1995). Sex differences in the functional organization of the brain for language. Nature 373: 607-609.

Simonsen HG, Kristoffersen KE, Bleses D, et al. (2013). The Norwegian Communicative Development Inventories: Reliability, main developmental trends and gender differences. First Lang 34: 3-23.

Simpson NH, Addis L, Brandler WM, et al. (2013). Increased prevalence of sex chromosome aneuploidies in specific language impairment and dyslexia. Dev Med Child Neurol 56: 346353.

Skakkebæk A, Gravholt CH, Rasmussen PM, et al. (2014). Neuroanatomical correlates of Klinefelter syndrome studied in relation to the neuropsychological profile. Neuroimage Clin 4: $1-9$. 
Skakkebæk A, Wallentin M \& Gravholt CH (2015). Neuropsychology and socioeconomic aspects of Klinefelter syndrome: new developments. Curr Opin Endocrinol Diabetes Obes 22: 209216.

Skewes L, Fine C \& Haslam N (2018). Beyond Mars and Venus: The role of gender essentialism in support for gender inequality and backlash. PLoS One 13: e0200921.

Somers M, Aukes MF, Ophoff RA, et al. (2015). On the relationship between degree of handpreference and degree of language lateralization. Brain Lang 144: 10-15.

Somers M, Sommer IE, Boks MP, et al. (2009). Hand-preference and population schizotypy: A meta-analysis. Schizophr Res 108: 25-32.

Sommer I, Ramsey N, Kahn R, et al. (2001). Handedness, language lateralisation and anatomical asymmetry in schizophrenia: meta-analysis. Br J Psychiatry 178: 344-351.

Sommer IE, Aleman A, Somers M, et al. (2008). Sex differences in handedness, asymmetry of the planum temporale and functional language lateralization. Brain Res 1206: 76-88.

Sommer IEC (2004). Do women really have more bilateral language representation than men? A meta-analysis of functional imaging studies. Brain 127: 1845-1852.

Sommer IEC, Ramsey NF, Mandl RCW, et al. (2003). Language lateralization in female patients with schizophrenia: an fMRI study. Schizophr Res 60: 183-190.

Stanovich KE (1986). Matthew Effects in Reading: Some Consequences of Individual Differences in the Acquisition of Literacy. Read Res Q 21: 360-407.

Stephens S \& Moxham BJ (2018). Gross anatomy examination performances in relation to medical students' knowledge of classical latin and greek. Clin Anat 31: 501-506.

Strauss JS (1969). Hallucinations and delusions as points on continua function: Rating scale evidence. Arch Gen Psychiatry 21: 581-586.

Stroustrup S \& Wallentin M (2018). Grammatical category influences lateralized imagery for sentences. Lang Cogn 10: 193-207.

Szagun G, Stumper B \& Schramm AS (2009). Fragebogen zur frühkindlichen Sprachentwicklung (FRAKIS) und FRAKIS-K (Kurzform), Frankfurt, Pearson Assessment.

Tanenhaus MK, Spivey-Knowlton MJ, Eberhard KM, et al. (1995). Integration of visual and linguistic information in spoken language comprehension. Science 268: 1632-1634.

Tardif T, Fletcher P, Liang W, et al. (2009). Early vocabulary development in Mandarin (Putonghua) and Cantonese. J Child Lang 36: 1115-1144.

Tartaglia NR, Howell S, Sutherland A, et al. (2010). A review of trisomy X (47,XXX). Orphanet J Rare Dis 5: 8 .

Taylor AE, Saint-Cyr JA \& Lang AE (1986). Frontal lobe dysfunction in Parkinson's disease: The cortical focus of neostriatal outflow. Brain 109: 845-883.

Thal DJ, Marchman VA \& Tomblin JB (2013). Late talking toddlers: Characterization and prediction of continued delay. In: Rescorla L \& Dale P (eds.) Late Talkers: Language Development, Interventions, and Outcomes. Baltimore, MD: Brookes Publishing Co.

Thapa KB, Okalidou A \& Anastasiadou S (2016). Teachers' screening estimations of speechlanguage impairments in primary school children in Nepal. Int J Lang Commun Disord 51: 310-327.

Tien AY (1991). Distribution of hallucinations in the population. Soc Psychiatry Psychiatr Epidemiol 26: 287-292.

Titze IR (1989). Physiologic and acoustic differences between male and female voices. J Acoust Soc Am 85: 1699-1707.

Tomasello M (2003). Constructing a Language: A Usage-based Theory of Language Acquisition, Harvard, Harvard University Press. 
Torppa M, Eklund K, Sulkunen S, et al. (2017). Why do boys and girls perform differently on PISA Reading in Finland? The effects of reading fluency, achievement behaviour, leisure reading and homework activity. J Res Read 41: 122-139.

Tosto MG, Hayiou-Thomas ME, Harlaar N, et al. (2017). The genetic architecture of oral language, reading fluency, and reading comprehension: A twin study from 7 to 16 years. Dev Psychol 53: $1115-1129$.

Trouton A, Spinath FM \& Plomin R (2002). Twins Early Development Study (TEDS): A Multivariate, Longitudinal Genetic Investigation of Language, Cognition and Behavior Problems in Childhood. Twin Res 5: 444-448.

Tseng Y-C, Lai D-C \& Guo H-R (2015). Gender and geographic differences in the prevalence of reportable childhood speech and language disability in Taiwan. Res Dev Disabil 40: 11-18.

Tylén K, Weed E, Wallentin M, et al. (2010). Language as a Tool for Interacting Minds. Mind Lang 25: 3-29.

Urek O, Vulāne A, Darğis R, et al. (to appear). Latvian CDI: methodology, developmental trends and cross-linguistic comparison.

van Borsel J, Moeyaert J, Mostaert C, et al. (2006). Prevalence of Stuttering in Regular and Special School Populations in Belgium Based on Teacher Perceptions. Folia Phoniatr Logop 58: 289-302.

van Os J, Hanssen M, Bijl RV, et al. (2000). Strauss (1969) revisited: a psychosis continuum in the general population? Schizophr Res 45: 11-20.

van Rijn S, Aleman A, Swaab H, et al. (2008). Effects of an extra X chromosome on language lateralization: an fMRI study with Klinefelter men (47,XXY). Schizophr Res 101: 17-25.

Vawter MP, Harvey PD \& DeLisi LE (2007). Dysregulation of X-linked gene expression in Klinefelter's syndrome and association with verbal cognition. Am J Med Genet B Neuropsychiatr Genet 144B: 728-734.

Vorstman JAS, Parr JR, Moreno-De-Luca D, et al. (2017). Autism genetics: opportunities and challenges for clinical translation. Nature Reviews Genetics 18: 362.

Voyer D \& Voyer SD (2014). Gender differences in scholastic achievement: a meta-analysis. Psychol Bull 140: 1174-1204.

Walder D, Seidman L, Cullen N, et al. (2006). Sex differences in language dysfunction in schizophrenia. Am J Psychiatry 163: 470-477.

Walker FO (2007). Huntington's disease. Lancet 369: 218-228.

Wallentin M (2009). Putative sex differences in verbal abilities and language cortex: a critical review. Brain Lang 108: 175-183.

Wallentin M (2018). Sex differences in post-stroke aphasia rates are caused by age. A meta-analysis and database query. PLoS One 13: e0209571.

Wallentin M, Kristensen LB, Olsen JH, et al. (2011). Eye movement suppression interferes with construction of object-centered spatial reference frames in working memory. Brain Cogn 77: 432-437.

Wallentin M, Michaelsen JLD, Rynne I, et al. (2014). Lateralized task shift effects in Broca's and Wernicke's regions and in visual word form area are selective for conceptual content and reflect trial history. Neuroimage 101: 276-288.

Wallentin M, Rocca R \& Stroustrup S (in press). Grammar, gender and demonstratives in lateralized imagery for sentences. J Psycholinguist Res.

Wallentin M, Skakkebæk A, Bojesen A, et al. (2016). Klinefelter syndrome has increased brain responses to auditory stimuli and motor output, but not to visual stimuli or Stroop adaptation. Neuroimage Clin 11: 239-251. 
Wallentin M, Weed E, Østergaard L, et al. (2008). Accessing the mental space-Spatial working memory processes for language and vision overlap in precuneus. Hum Brain Mapp 29: 524532.

Warrington E \& McCarthy R (1987). Categories of knowledge: Further fractionations and an attempted integration. Brain 110: 1273.

Warrington E \& Shallice T (1984). Category specific semantic impairments. Brain 107: 829-854.

Warrington EK (1975). The selective impairment of semantic memory. Q J Exp Psychol 27: 635657.

Waters F, Collerton D, ffytche DH, et al. (2014). Visual Hallucinations in the Psychosis Spectrum and Comparative Information From Neurodegenerative Disorders and Eye Disease. Schizophr Bull 40: S233-S245.

Watila MM \& Balarabe SA (2015). Factors predicting post-stroke aphasia recovery. J Neurol Sci 352: $12-18$.

Wechsler D (1992). Wechsler Intelligence Scale for Childrenmanual London, Psychological Corporation.

Whitehouse AJO, Watt HJ, Line EA, et al. (2009). Adult psychosocial outcomes of children with specific language impairment, pragmatic language impairment and autism. Int J Lang Commun Disord 44: 511-528.

Wilson AC \& Bishop DVM (2018a). Resounding failure to replicate links between developmental language disorder and cerebral lateralisation. PeerJ 6: e4217.

Wilson AC \& Bishop DVM (2018b). Sex chromosome trisomies are not associated with atypical lateralisation for language. bioRxiv.

Winawer J, Witthoft N, Frank MC, et al. (2007). Russian blues reveal effects of language on color discrimination. Proc Natl Acad Sci U S A 104: 7780-7785.

Wooten GF, Currie LJ, Bovbjerg VE, et al. (2004). Are men at greater risk for Parkinson's disease than women? J Neurol Neurosurg Psychiatry 75: 637.

Yairi E \& Ambrose N (2013). Epidemiology of stuttering: 21st century advances. J Fluency Disord 38: 66-87.

Yardley L, Gardner M, Leadbetter A, et al. (1999). Effect of articulatory and mental tasks on postural control. Neuroreport 10: 215-219.

Yoshizumi T, Murase S, Honjo S, et al. (2004). Hallucinatory Experiences in a Community Sample of Japanese Children. J Am Acad Child Adolesc Psychiatry 43: 1030-1036.

Zielonka D, Marinus J, Roos RAC, et al. (2013). The influence of gender on phenotype and disease progression in patients with Huntington's disease. Parkinsonism Relat Disord 19: 192-197.

Елисеева МБ \& Вершинина ЕА Некоторые нормативы речевого развития детей от 18 до 36 месяцев (по материалам МакАртуровского опросника). Проблемы онтолингвистики, 2009 Санкт-Петербург.

劉惠美 \& 陳昱君 (2015). 華語嬰幼兒表達性詞彙的語意內容及詞類組成之發展. 教育心理學 報 47: 217-242. 
Submitted to: Lanzenberger, R., Kranz, G.S., Savic, I.(eds.), Handbook of Clinical Neurology: Sex differences in neurology and psychiatry, Elsevier, March 11, 2019

Figures and figure captions

(High-resolution figures are submitted separately) 
Figure 1
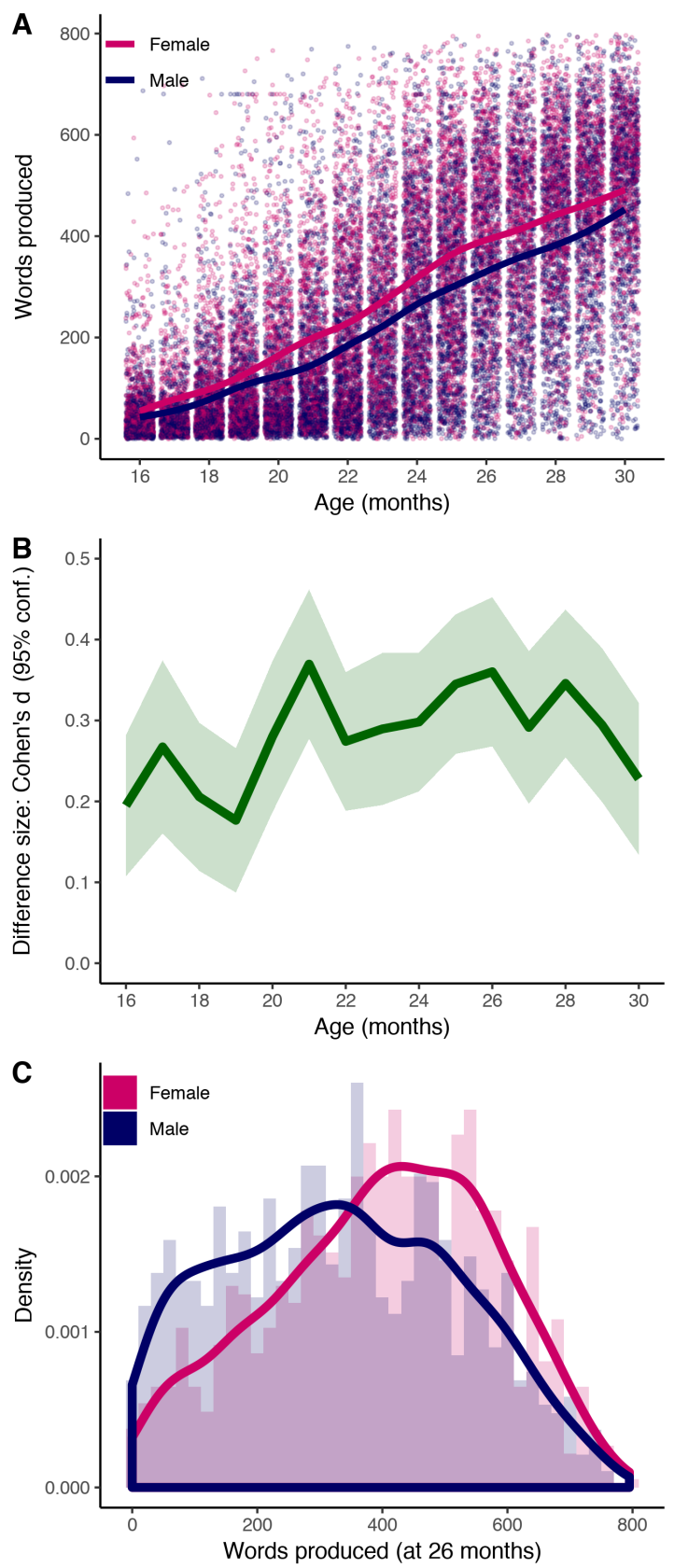

Figure1. Girls acquire words slightly earlier than boys. A: Across multiple languages (Cantonese, Croatian, Czech, Danish, English (AU, US), German, Hebrew, Italian, Korean, Latvian, Mandarin, Norwegian, Portuguese (European), Russian, Slovak, Spanish (European, Mexican), Swedish, Turkish) with a total of 28098 children, parental reports find that girls produce a slightly higher number of different words. B: Effect sizes in word production differences are in the small range (Cohen's $d \approx 0.2-0.4$ ). Differences decrease slightly in the older children, but this may be due to ceiling effects. C: At 26 months girls produce a median of 414 words, while boys produce 330 words. In the low $10^{\text {th }}$ percentile, boys outnumber girls 2:1, but note also the large overlap in distributions. NB. Cross-linguistic comparisons are challenging with CDIs, because the inventories are not identical (consist of lists of 600-800 words, depending on language). Data extracted from http://wordbank.stanford.edu (Oct. 15 2018).

**FIGURE 1 SHOULD BE REPRODUCED IN 1 COLUMN** 
Submitted to: Lanzenberger, R., Kranz, G.S., Savic, I.(eds.), Handbook of Clinical Neurology: Sex differences in neurology and psychiatry, Elsevier, March 11, 2019

Figure 2
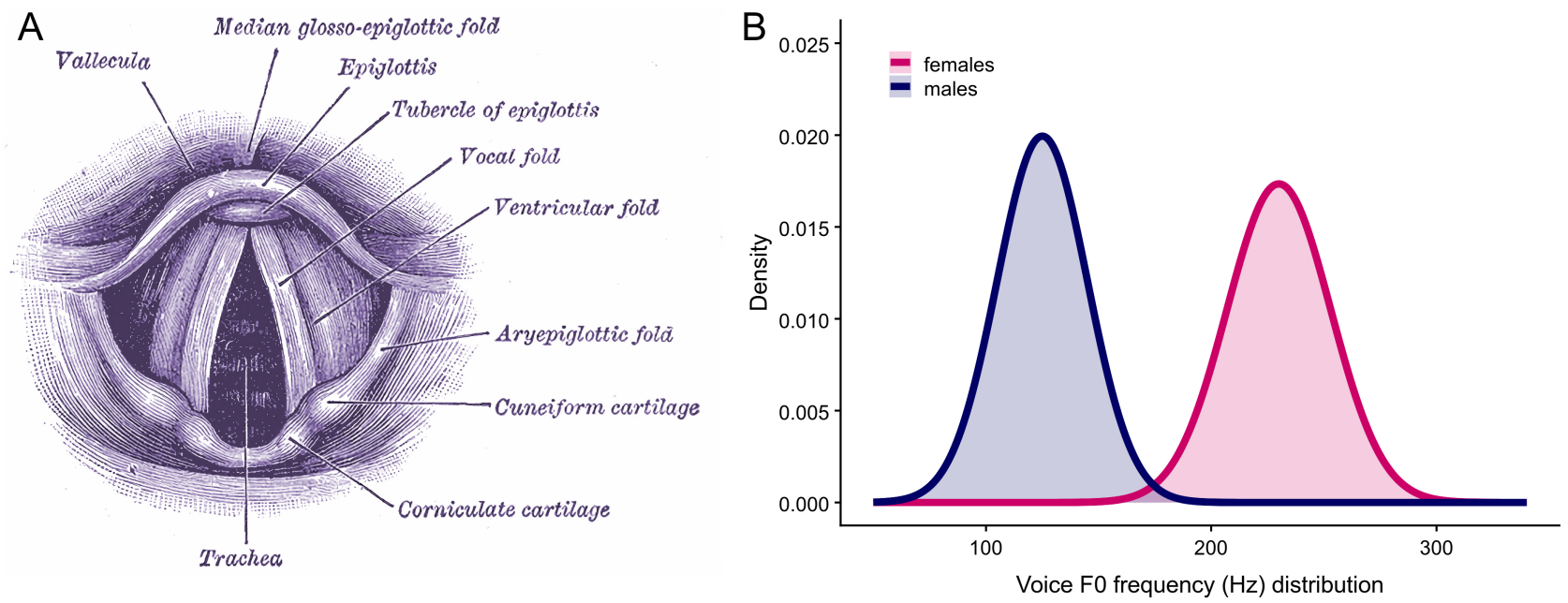

Figure 2. A. The vocal folds, enabling speech, differ in length between men and women with 1.6:1 ratio. Drawing reproduced from Gray (1918). B. Young adult men and women differ in voice fundamental frequency (F0) with very little overlap in distributions (assuming normal distributions). Women's mean F0: $230 \mathrm{~Hz}$ (std. $23 \mathrm{~Hz}$ ). Men's mean F0: $125 \mathrm{~Hz}$ (std. $20 \mathrm{~Hz}$ ). Plot based on Bachorowski \& Owren, 1999.

**FIGURE 2 SHOULD BE REPRODUCED ACROSS COLUMNS** 
Submitted to: Lanzenberger, R., Kranz, G.S., Savic, I.(eds.), Handbook of Clinical Neurology: Sex differences in neurology and psychiatry, Elsevier, March 11, 2019

Figure 3

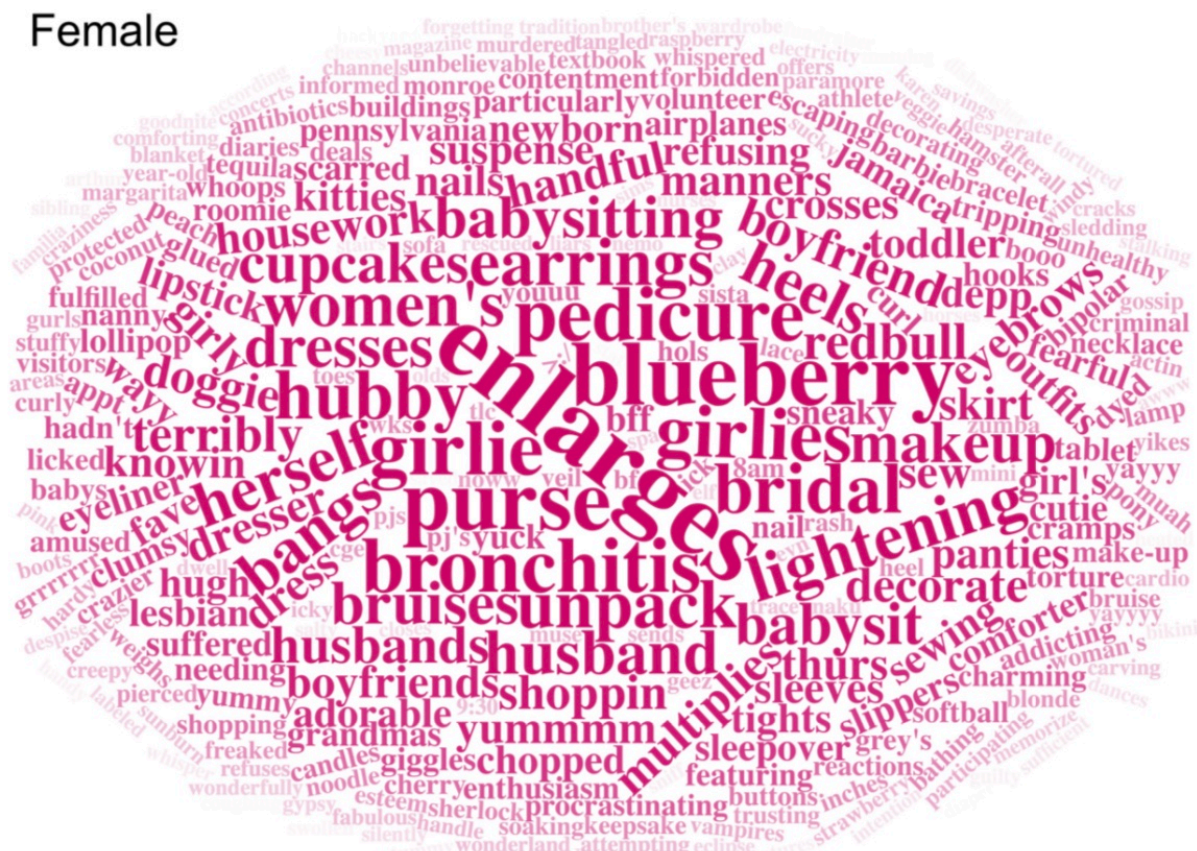

Male

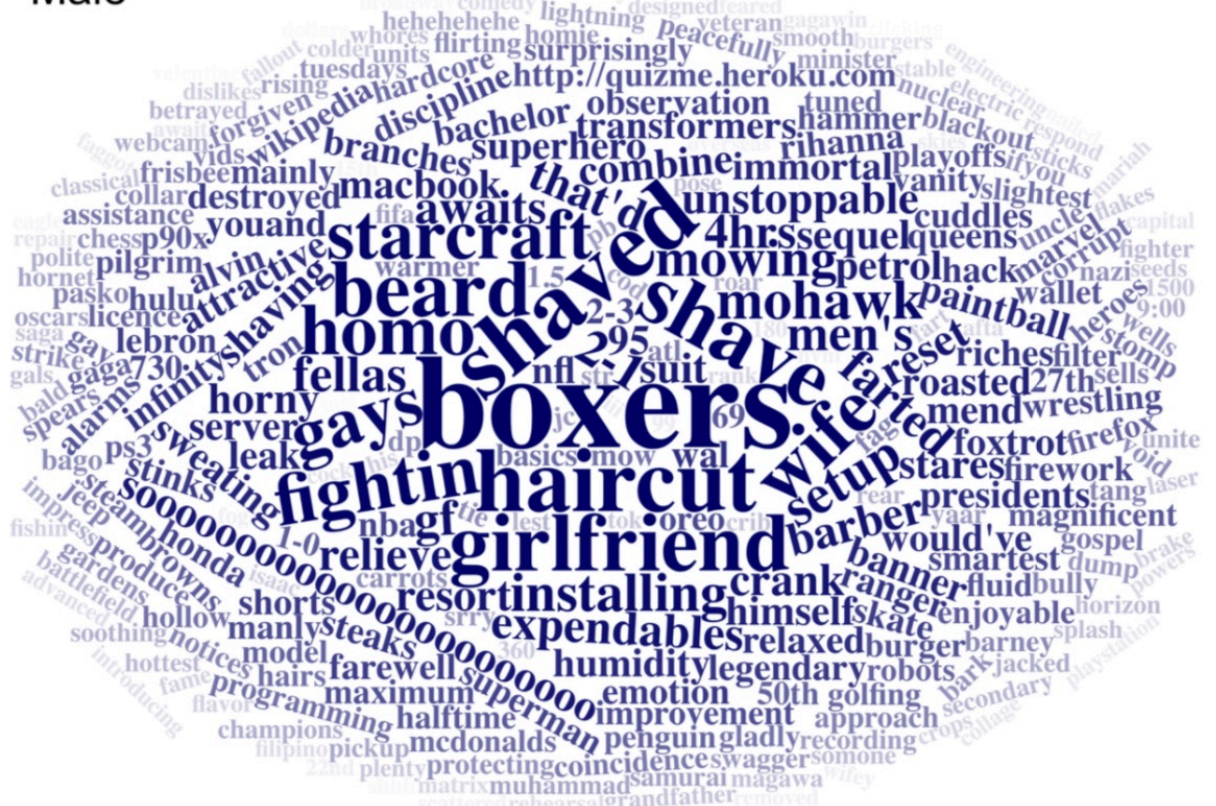

Figure 3. Words used in a multivariate classification to predict gender extracted from Englishspeaking Facebook users $((N=72,874)$. Combinations of words used allow prediction of with 92\% accuracy. Plot contains the 300 most predictive words for each gender. Larger words have higher weight. Word data from Sap et al. 2014, reproduced with permission from the authors.

**FIGURE 3 SHOULD BE REPRODUCED ACROSS COLUMNS** 
Submitted to: Lanzenberger, R., Kranz, G.S., Savic, I.(eds.), Handbook of Clinical Neurology: Sex differences in neurology and psychiatry, Elsevier, March 11, 2019

Figure 4

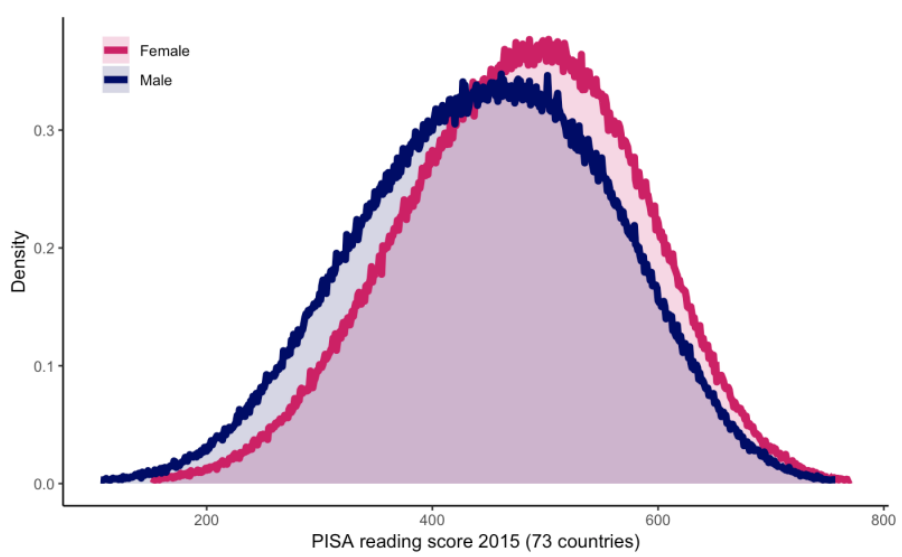

Figure 4. Overall reading score at age 15 from all OECD and partner countries (73 countries, $n \approx 519,000$ ). Girls outperform boys on the PISA reading test in all participating countries. Reading habits are known to be correlated with vocabulary size. Effect size is found to be small to medium $(d \approx 0.4)$. In the lowest $10^{\text {th }}$ percentile, however, boys outnumber girls 2.4:1. Data from: http://www.oecd.org/pisa/data/2015databasel. Analyzed using Caro \& Biecek (2017). **FIGURE 4 SHOULD BE REPRODUCED IN 1 COLUMN** 
Figure 5
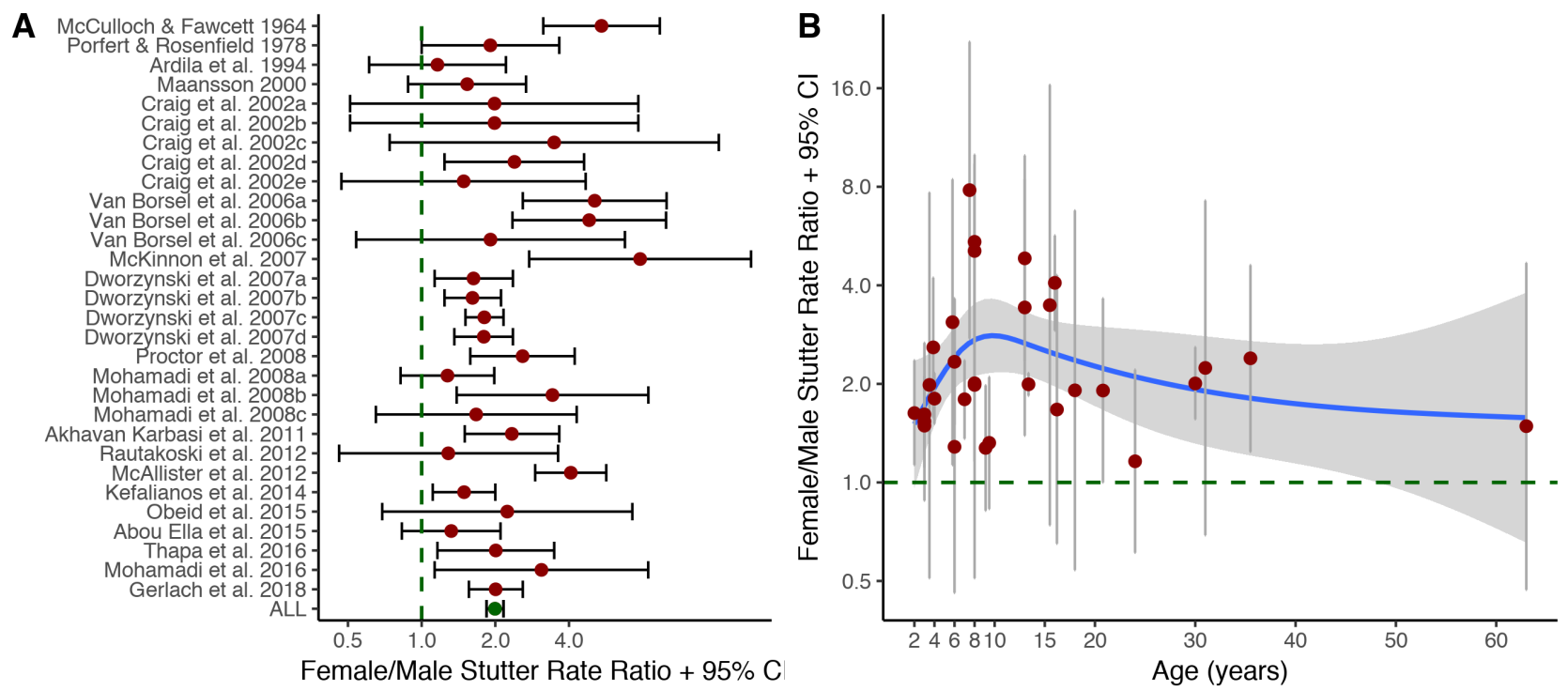

Figure 5. A. Males have a higher prevalence of stuttering than females (1:1.99) across different studies and age ranges. B. Most children (50-94\%) show spontaneous recovery. Recovery, however, is delayed for boys, causing a bump in the gender difference in middle childhood. **FIGURE 5 SHOULD BE REPRODUCED ACROSS COLUMNS**

Figure 6

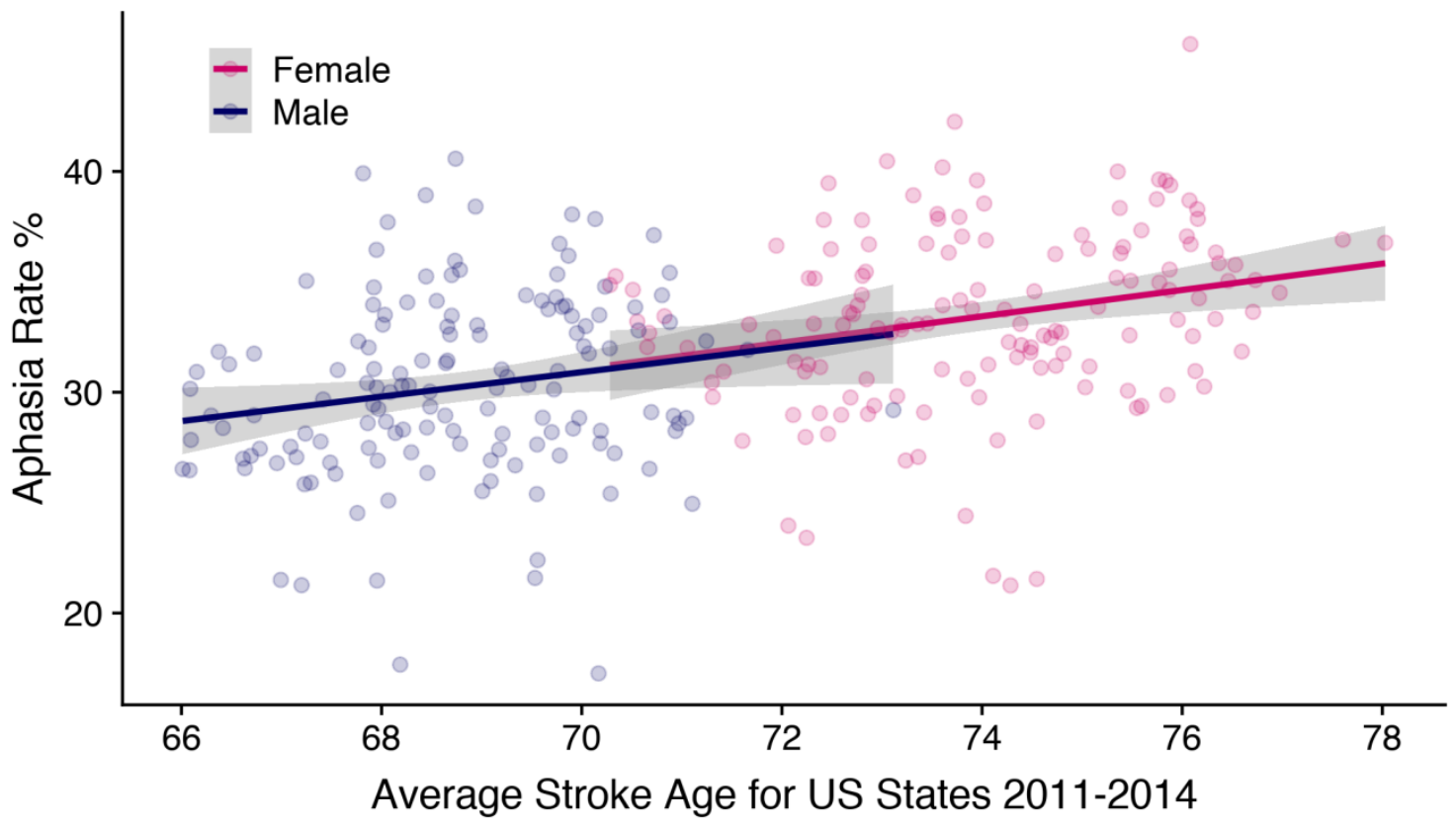

Figure 6. Using data from a US health database, it was found that an observed sex difference in post stroke aphasia could be explained by age differences at time of stroke. Note that there is no offset between the regression lines for males and females, suggestive of a main effect of sex. Figure reproduced from Wallentin 2018.

**FIGURE 6 SHOULD BE REPRODUCED IN 1 COLUMN** 